\title{
Sheeting Joints: Characterisation, Shear Strength and Engineering
}

\author{
S. R. Hencher $\cdot$ S. G. Lee $\cdot$ T. G. Carter $\cdot$ \\ L. R. Richards
}

Received: 31 December 2009/Accepted: 5 May 2010/Published online: 25 May 2010

(C) The Author(s) 2010. This article is published with open access at Springerlink.com

\begin{abstract}
Sheeting joints are extensive fractures that typically develop parallel to natural slopes. Embryonic sheeting joints initially constitute channels for water flow and then become the focus for weathering and sediment infill accompanied by progressive deterioration and dilation. Slabs of rock fail along them periodically because of their adverse orientation and long persistence. They are however rough and wavy and these characteristics contribute highly to their shear strength and improve their stability. This paper reviews several landslide case histories and on the basis of these provides guidelines for characterising sheeting joints and determining their shear strength. Engineering options for stabilising sheeting joints in natural and cut slope configurations are then examined with reference to case examples.
\end{abstract}

Keywords Sheeting joint origins - Shear strength · Landslides $\cdot$ Engineering measures $\cdot$ Roughness characterisation

\footnotetext{
S. R. Hencher

Halcrow China Ltd., Hong Kong, China

S. R. Hencher $(\bowtie)$

University of Leeds, Leeds, UK

e-mail: stevehencher@btinternet.com

S. G. Lee

University of Seoul, Seoul, Korea

T. G. Carter

Golder Associates, Toronto, Canada

L. R. Richards

Canterbury, New Zealand
}

\section{Introduction}

Sheeting joints are a striking feature of many landscapes (Fig. 1a, b) and they have been studied for more than two centuries (Twidale 1973). They run roughly parallel to the ground surface in flat-lying and steeply inclined terrain and generally occur close to the surface, typically at less than $30 \mathrm{~m}$ depth. They can often be traced laterally for hundreds of metres. Most sheeting joints are young geologically and some have been observed to develop explosively and rapidly as tensile fractures in response to unloading (Nichols 1980). Others are propagated to assist in quarrying using heat or hydraulic pressure (Holzhausen 1989). Their recent origins and long persistence without rock bridges differentiates them from most other joints many of which develop following pre-imposed, geological weakness directions during weathering and unloading as illustrated in Fig. 2a, b and discussed by Wise (1964) and Hencher and Knipe (2007). These characteristics of sheeting joints (especially their long persistence and lack of intact rock bridges) also distinguish them from most bedding, cleavage or schistosity-parallel discontinuities.

\section{Development of Sheeting Joints}

Sheeting joints are common in granite and other massive igneous rocks but also develop more rarely in other rock types including sandstone and conglomerate. Ollier (1975) provides an excellent review of early research and observations on their occurrence and development and Twidale and Vidal Romani (2005) discuss their occurrence specifically in granitic terrain.

Some sheeting joints develop at shallow dip angles, for instance during quarrying, where high horizontal 

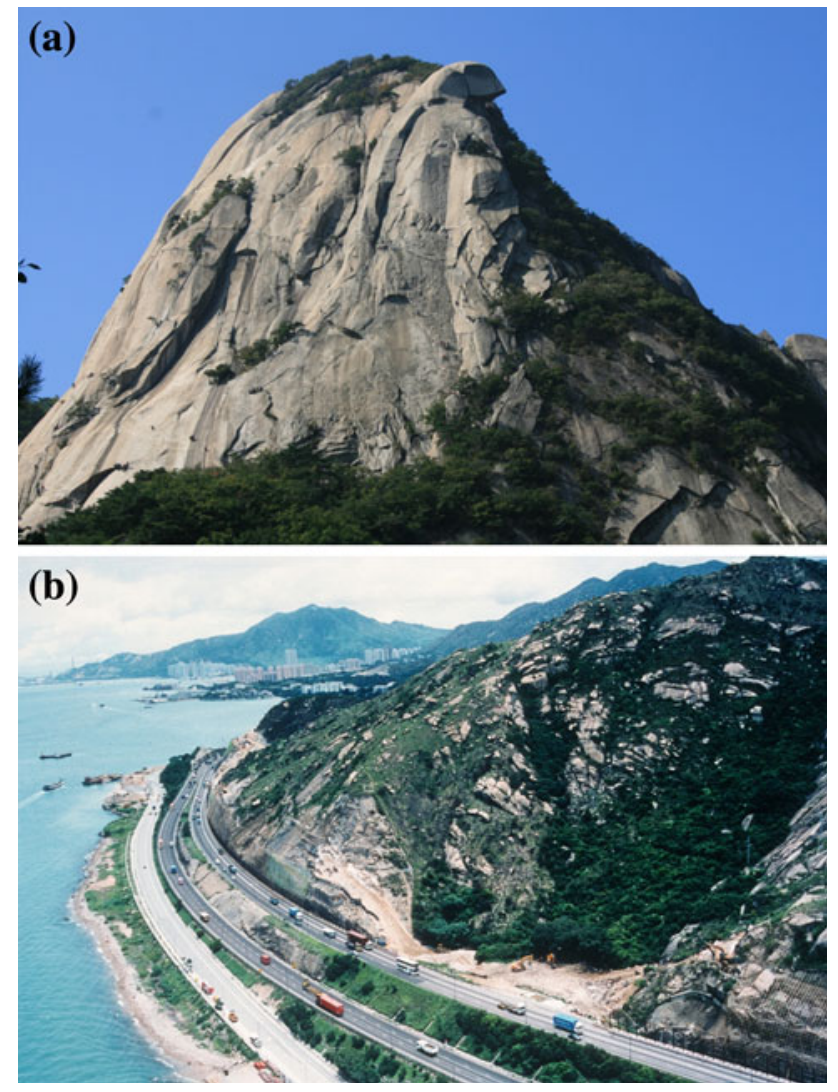

Fig. 1 Sheeting joints in granite: a Mt. Bukhansan, near Seoul, Korea; b Tuen Mun Highway, Hong Kong

compressive stresses are locked in at shallow depths (Fig. 3a). In Southern Ontario, Canada, for example, high horizontal stresses locked in following glacial unloading often give rise to quarry floor heave and pop-up structures accompanied by opening up of pre-existing incipient discontinuities such as bedding planes and schistose cleavage (Roorda et al. 1982). Where there are no pre-existing weakness directions, new sub-horizontal fractures may develop in otherwise unfractured rock. Holzhausen (1989) describes propagation of new sheeting joints under a horizontal stress of about $17 \mathrm{MPa}$ at a depth of only $4 \mathrm{~m}$ where the vertical confining stress due to self weight of the rock is only about $100 \mathrm{kPa}$. The mechanism is similar to a uniaxial compressive strength test where tensile fracture propagates parallel to the maximum principal stress $\left(\sigma_{1}\right)$. Such exfoliation and tensile development of sheeting joints is analogous to the sometimes explosive spalling and slabbing often seen in deep mines (Diederichs 2003; Hoek 1968).

From a worldwide perspective, however, the joints most commonly recognised as sheeting structures are observed in steep natural slopes. These joints are also thought to develop as tensile fractures where the maximum compressive stress due to gravity is reoriented to run parallel to
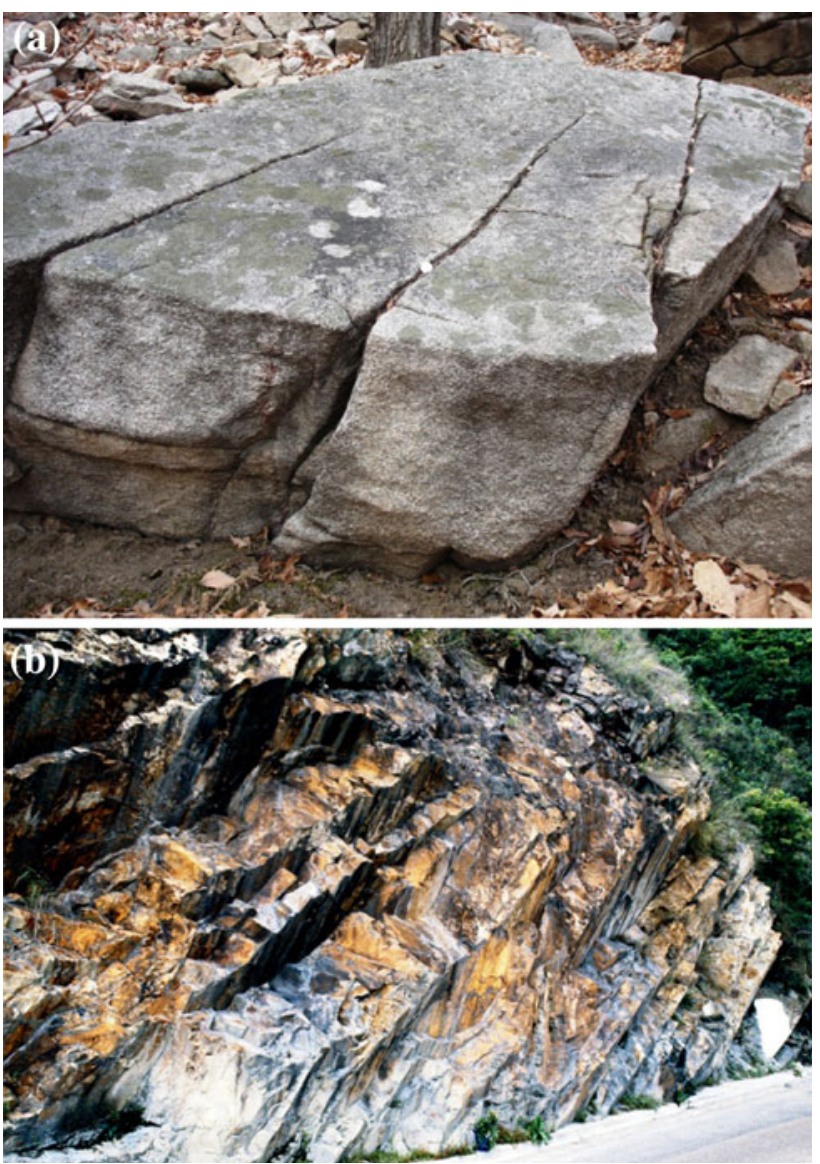

Fig. 2 Parallel set traces of proto-joints in the process of developing as full mechanical fractures but maintaining considerable true cohesion a Jurassic granite, Bukansan, Seoul; b Tuff, Island Road, Hong Kong

(a)

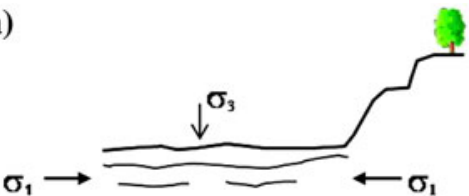

High in situ horizontal stress (as observed in some quarries)

(b)

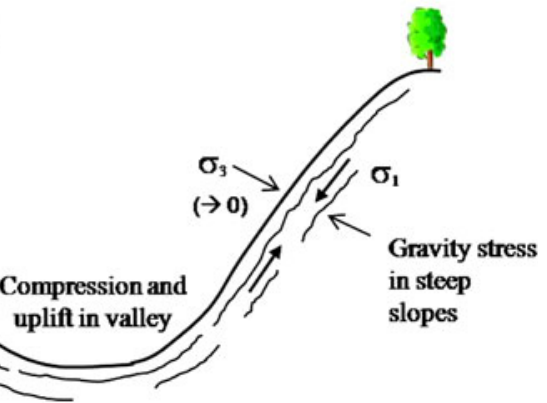

Fig. 3 Stress conditions for the formation of sheeting joints $\mathbf{a}$ in regions with very high horizontal in situ stresses and $\mathbf{b}$ in steep slopes and relatively strong, unfractured rock 

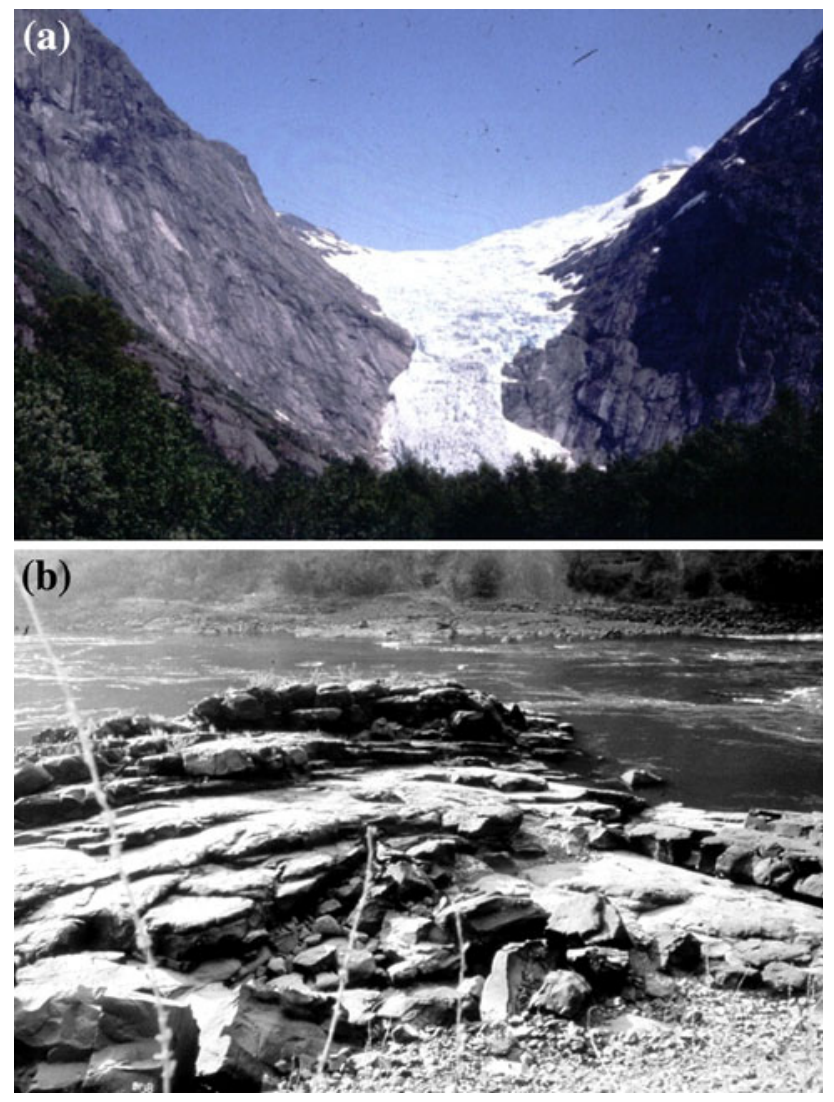

Fig. 4 Sheeting joints under valleys a Norway; b Zambezi River at Batoka Gorge, Zimbabwe. The sheeting joints are in otherwise massive basalt

the slope as illustrated in Fig. 3b, demonstrated by numerical models (Yu and Coates 1970; Selby 1993) and discussed in detail by Bahat et al. (1999). Sheeting joints also develop parallel to the stress trajectories that curve under valleys where there has been rapid glacial unloading or valley down cutting as illustrated in Fig. 4. Failure and erosion is a continuing process with the formation of new sheeting joints following the failure of sheet-bounded slabs. Wakasa et al. (2006) calculated an average erosion rate of $56 \mathrm{~m}$ in 1 million years from measurements of exposed sheeting joints in granite in Korea which is significantly higher than erosion rates on other slopes without sheeting joints. Whilst many exposed sheeting joints are evidently very recent, others are much older. Jahns (1943) and Martel (2006) note the apparent dissection of landscapes post-dating sheet joint formation. Antiquity is also indicated by preferential and thick weathering as illustrated in Fig. 5a, which shows a segment of core through a sheet joint infilled with completely decomposed granite (CDG) with the joint infill material abutting directly against almost fresh rock; Fig. 5b shows a similar thick band of highly decomposed granite (HDG) between the walls of a sheeting joint at North Point, Hong Kong. Weathering grades used
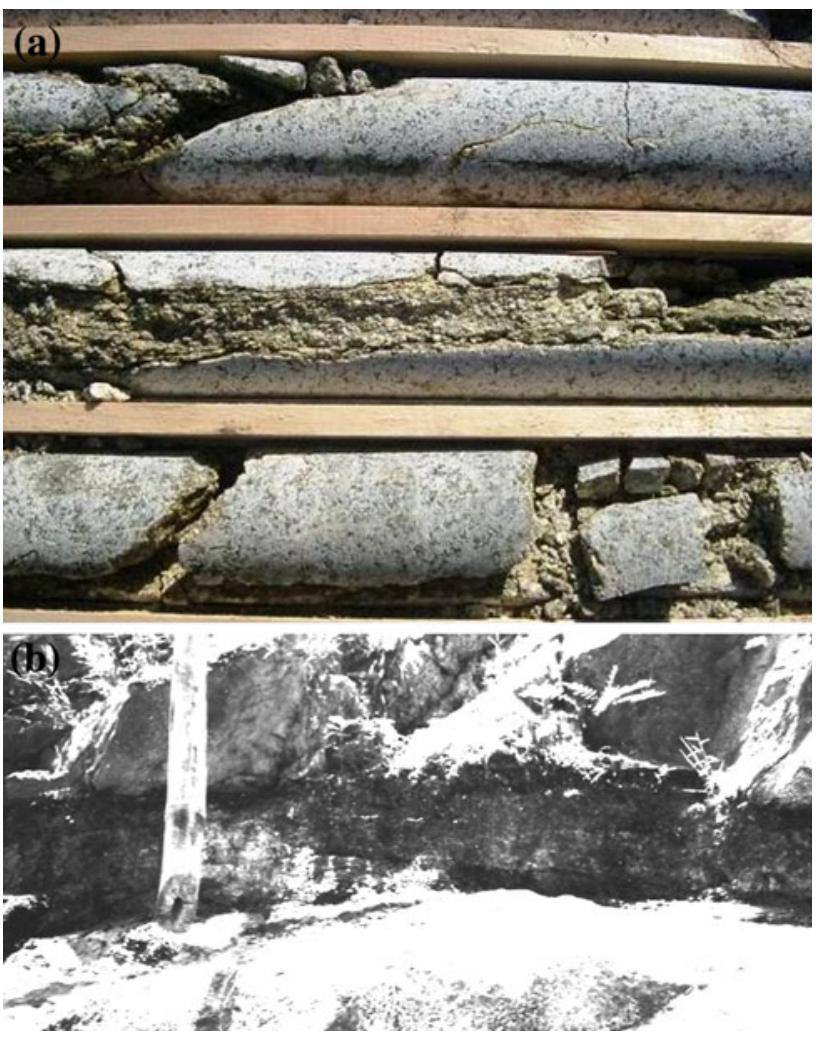

Fig. 5 a Completely decomposed granite in sheeting joint (horizontal borehole for tunnel). b Thick ( $300 \mathrm{~mm}$ ) continuous layer of grade IV granite sandwiched between grade II wall rock. Note sharp contacts and rough nature of lower exposed sheet joint surface. Bamboo scaffold pole in foreground

here are as defined in Geotechnical Engineering Office (1988) and BS 5930 (1999).

Additional evidence for the great age of some sheeting joints is the fact that they can sometimes be observed cutting through otherwise highly fractured rock. Most sheeting joints occur in massive, strong rock and it is argued that if the rock mass had been already highly fractured or weathered then the topographic stresses would be accommodated by movements within the weak mass rather than by initiating a new tensile fracture (Vidal Romani and Twidale 1999). Therefore where sheeting joints are found in highly fractured rock masses, it is likely that they predate the gradual development of the other joints as mechanical fractures during unloading and weathering (Hencher 2006; Hencher and Knipe 2007).

Some extensive, hillside-parallel joints have many of the characteristics of "true" sheeting joints but owe their geometry instead to the opening up of pre-existing weakness directions such as doming joints in plutonic igneous rock or bedding in sedimentary rock. In this case the preexisting fracture network defines the hillside shape rather than the other way around (Twidale 1973). The opening up of these pre-existing joint systems is probably largely in 
response to the same topographic stress conditions that encourage the formation of virginal sheeting joints in massive rock but development may be more gradual. That being so, such joint sets are more likely to retain intact rock bridges between sections of fully developed mechanical fractures than will true sheeting joints and these rock bridges will provide real cohesion, improving overall hillside stability.

\section{Geometry and Occurrence}

\subsection{Sheeting Joints Within the Weathering Profile}

Sheeting joint terrain can be regarded as one end of a range of possible weathering profiles where the erosion rate exceeds that of the development of saprolite. They tend to develop in steep sections of hillsides where of course surface erosion is also high. Otherwise there does not appear to be any defining criterion for whether sheeting joints or thicker weathering profiles will dominate across a hillside although it seems clear that once the rock mass becomes significantly fractured or deeply weathered then this will preclude the further development of sheeting joints. They are generally not found in rock underlying thick weathered profiles; the weight of the soil probably constrains their formation (Fig. 6). They are however sometimes encountered as relict features within or at the base of thick weathered profiles where they probably predate the weathering. In such situations they may constitute a major hazard for slope stability in that they lack cohesion unlike the surrounding saprolite, they may allow water pressures to develop rapidly and the roughness and waviness that is such an important characteristic of sheeting joints in fresher rock may be ineffective due to weakening of the wall rock.

\subsection{General Shape, Occurrence and Relationship to Micro Fractures}

Sheeting joints often extend $100 \mathrm{~m}$ or more laterally as discrete fractures. Overlying tabular slabs of rock are typically 1-10 m thick; with an observed tendency for slab thickness to decrease the closer they are to the ground surface. The fractures often terminate against pre-existing cross joints or in intact rock (Fig. 7). Sometimes, adjacent parts of fractures, perhaps with two or more initiation points, interact forming step-like or "shingle" features as described by Holzhausen (1989). At some locations close microfractures can be observed running throughout the hillside, parallel to the natural slope, instead of discrete fractures defining rock slabs (Fig. 8a). Such zones of parallel microfractures probably reflect the overall rotated gravitational stress state in a similar way as do discrete

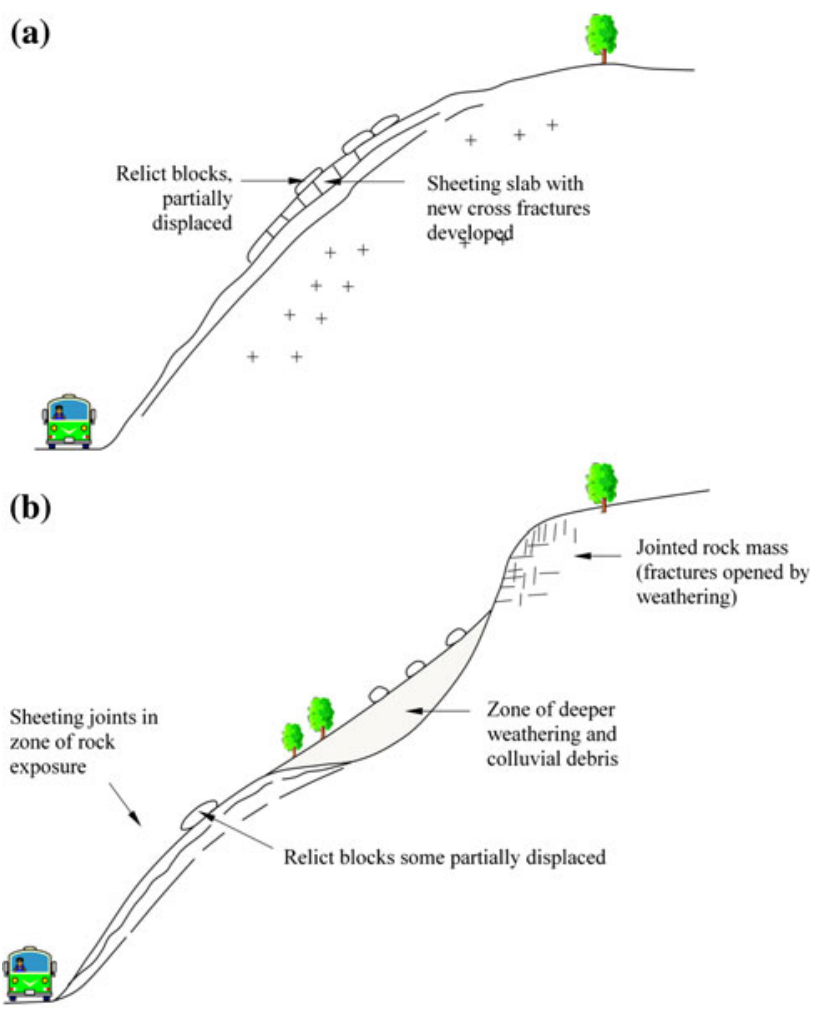

Fig. 6 Typical sheeting joint terrains. a Sheeting joints dominate landscape; b sheeting joints only in areas of rock exposure where erosion rate is higher than accumulation of weathering and colluvial deposits

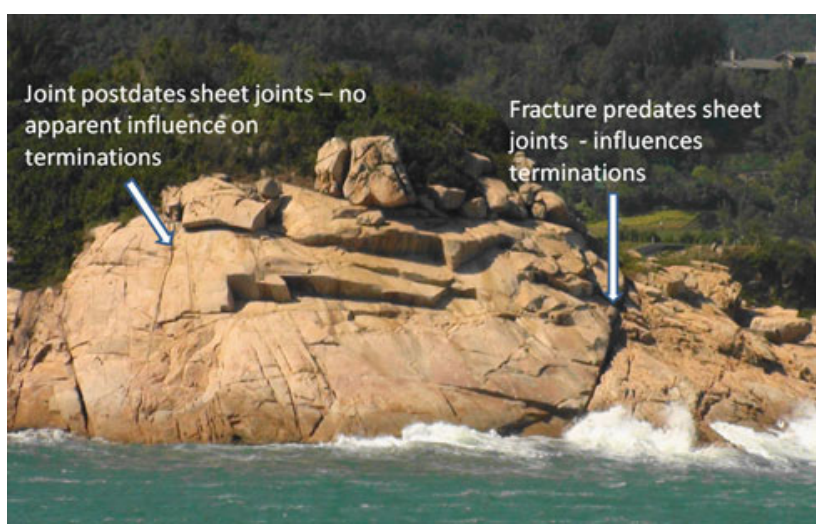

Fig. 7 Cross fractures influencing sheet joint development, Shek O, Hong Kong

sheeting joints. Elsewhere microfractures develop in a disintegrated zone between and parallel to the sheeting joint walls and have probably developed by exfoliation disintegration away from the original discrete fracture (Fig. 8b). In other locations parallel microfractures in what appears to be sheeting joint terrain may be demonstrated to owe their origins to geological stress conditions predating recent topographic development as for other sets of proto- 
Fig. 8 Parallel unloading microfractures throughout hillside. a Lion Rock Tunnel portal, Hong Kong. Lens cap for scale. b Near Doseonsa temple, nr. Seoul. Note microfracture disintegration is parallel to discrete sheeting joint in background
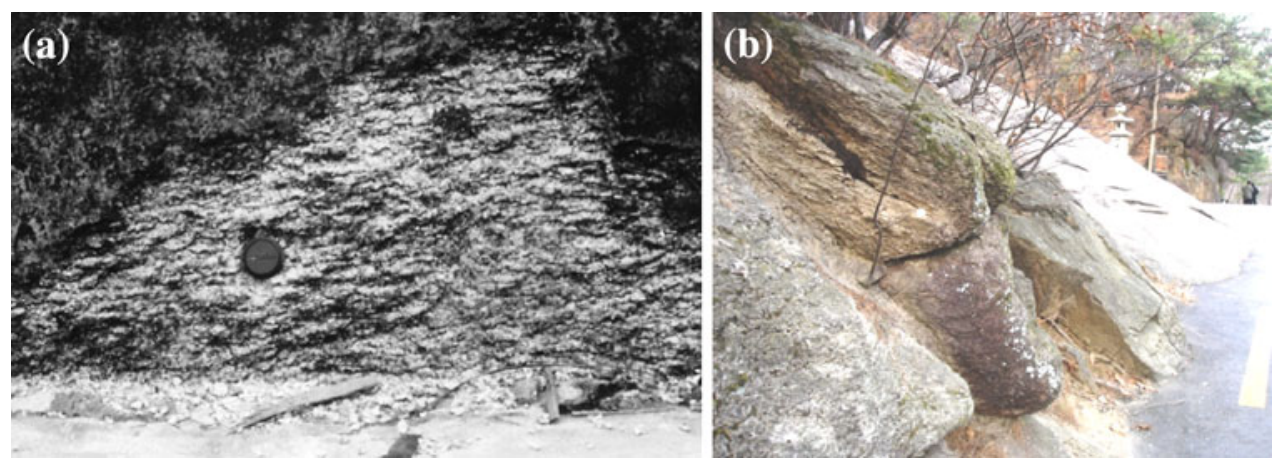

joints as discussed earlier. During drilling for the Tuen Mun Highway in Hong Kong zones of microfractures were encountered in some areas at the same depths where joints, interpreted as sheeting joints, might have been expected through interpolation from other boreholes (Carter et al. 1998). Detailed petrographic examination however revealed a block-work fabric of microfractures with the main set running parallel to other discrete sheeting joints and to the hillside, whilst others were essentially ortho gonal and parallel to sets of cross joints developed elsewhere as mechanical fractures (Fig. 9). In some samples all microfractures were seen to be healed with secondary quartz which is taken as an indication of their antiquity. Clearly microfracturing and sheeting joint development are often related as discussed in some detail by Jahns (1943) and Johnson (1970), but the relationship can be complex. In some situations, pre-existing microfractures can merge and coalesce as "sheeting joints" as Jahns suggests but elsewhere microfractures may develop instead of a discrete fracture and thirdly sheeting joints may develop explosively and essentially independently of any gradual microfracture growth stage. The situation may be particularly difficult to unravel when dealing with igneous plutonic rocks as at the Tuen Mun Highway and as studied by Jahns (1943) and Johnson (1970) and where the "sheeting joints" may exploit a microfracture network originally imposed by cooling stresses following a doming joint pattern (Cloos 1922) and where the cross joints might also owe their origins to the cooling and emplacement process. The evidence of quartz healing in the Tuen Mun Highway samples does suggest that at least some of the microfabric at the Tuen Mun Highway site might well owe its origin to cooling stresses with the quartz healing being the result of late stage throughflow of hot fluids during emplacement (pneumatolysis).

\subsection{Surface Characteristics}

The flat-lying joints encountered in quarries in areas of high residual horizontal stress and recognised as a type of sheeting or exfoliation joint are described as often smooth

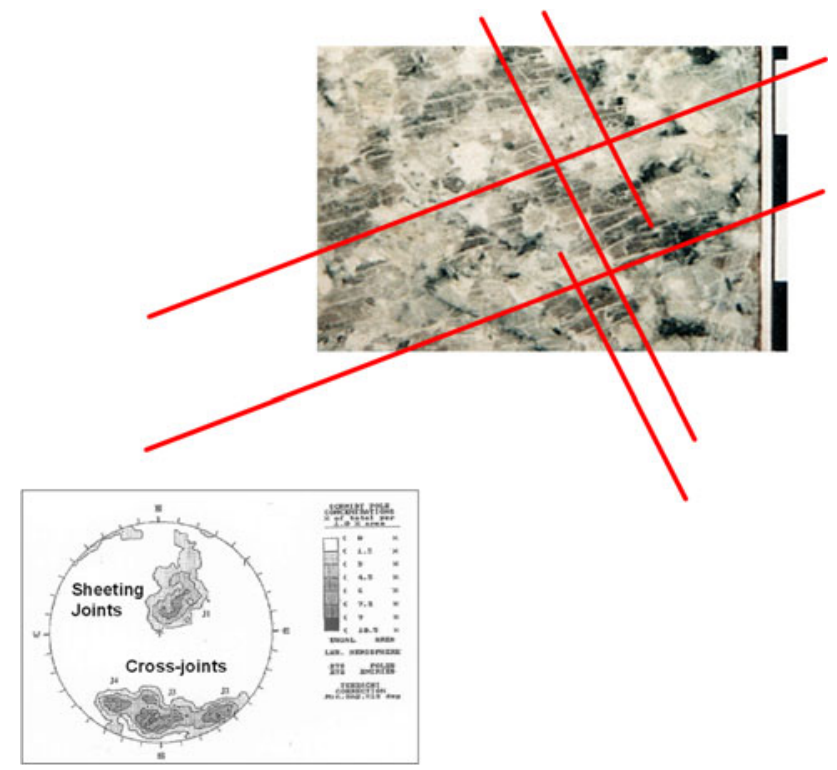

Fig. 9 Main set of microfractures dipping to left run parallel to main discrete sheeting joints seen elsewhere in slope (see stereo plot). Cross fractures run roughly parallel to cross joints dipping back into slope and acting as release joints to the sheeting joints

by Holzhausen (1989) although some show lineations. Sheeting joints that develop in steeply inclined hillsides where they probably owe their origin to gravitational stresses are typically rough and wavy (Richards and Cowland 1982). They often show broad waves with amplitude of the order of perhaps $1 \mathrm{~m}$ over wavelengths of 5-10 $\mathrm{m}$. Smaller roughness features and steps are superimposed on the general waviness as illustrated in Fig. 10. Some of the steps are due to intersections with cross joints whilst others may have resulted from different sections of the same sheeting joint interacting and overlapping during propagation as explained by Holzhausen (1989).

\section{Engineering Considerations}

It is a paradox that sometimes the entire stability of steeply cut slopes in otherwise excellent quality rock can be 


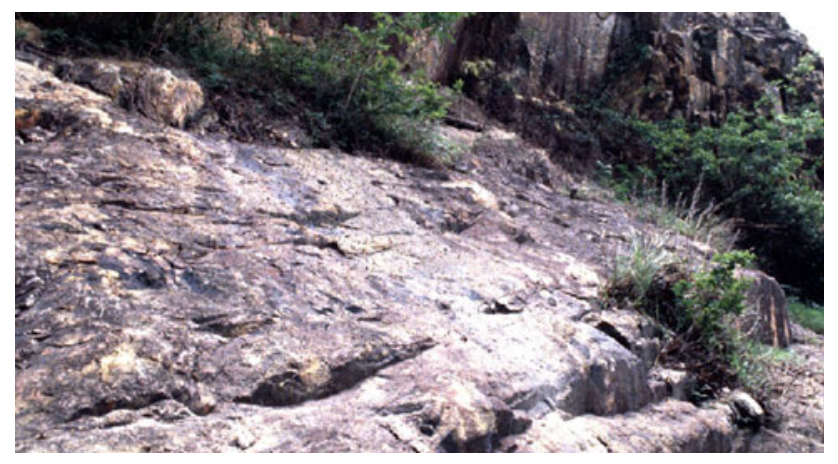

Fig. 10 Wavy and stepped surface through volcanic tuff, Hong Kong

compromised by the presence of discrete sheeting joints. They are also a major source of landsliding in natural terrain.

\subsection{Hydrogeology}

A newly formed sheeting joint may comprise a near perfectly matching fracture. Nevertheless, the permeability will be higher than the surrounding rock and allow groundwater ingress. In some situations water pressure may reduce effective stresses sufficiently to initiate shear. During shear, rough joints dilate thereby relieving water pressure and halting movement in many situations (Fig. 11). Following such transient displacement there will be a period of stasis, during which the walls of the joint may be attacked by weathering, the overlying rock disintegrates and voids that have been opened due to dilation are infilled with sediment transported from upslope. It is common to find depressions on dilated sheeting joints infilled with pockets of sediment, often hard kaolin, and this is interpreted as material that has gradually accumulated over a long period (Hencher 1983; Halcrow Asia Partnership 1998; Parry et al. 2000). Consequently open joints and the presence of sediment infill may indicate that some translational movement has occurred (Hencher 2006). It might take many iterative minor movements from extreme rainfall events before the controlling, wavy first order asperities (Patton and Deere 1970) are overridden and the slab detaches down slope as illustrated by the Leung King Estate, Hong Kong, case example presented below.

The water flow through all joints is tortuous, channelised and localised (Kikuchi and Mito 1993; Hencher 2010) and this will be especially true of most sheeting joints with their rough and wavy surfaces. Richards and Cowland (1986) report on a careful instrumentation programme to measure water pressure in a series of sheeting joints. They found that storms resulted in pressure surges through the joints with different joints responding at different times and in different ways during separate storms (Fig. 12). Carter et al. (1998) observed that distinctly different behaviour occurred between CDG-infilled sheet structures and more broken, less weathered sheet structures, in that the latter showed significant peaky response to rainfall events (with almost complete pressure dissipation occurring in minutes to hours), while the former showed a much delayed decay in pore pressure dissipation after the rainfall event; in some cases taking several days before complete dissipation returned to pre-rainfall pressure head conditions. The implications for design are significant in that peak water pressures do not occur throughout the whole slope at the same time. The tortuosity of drainage paths also has implications for the effective design of landslide preventive drainage measures as discussed later. The drains have to intersect the natural drainage paths if they are to do any good. It must also be anticipated that drainage paths may change with time so that some drains may dry up and others need to be installed.

\subsection{Shear Strength of Sheeting Joints}

Based on observations of many natural slopes it appears that failure of slopes along sheeting joints occurs predominantly by translational sliding of slabs of rock, often initiated by water pressure in the joint network. The problem is therefore relatively tractable to evaluate as it essentially only involves planar failure calculations rather than more complex wedge intersection displacements
Fig. 11 Partial movement and dilation of sheeting slabs: typical of early stage of failure a Korea, b Hong Kong
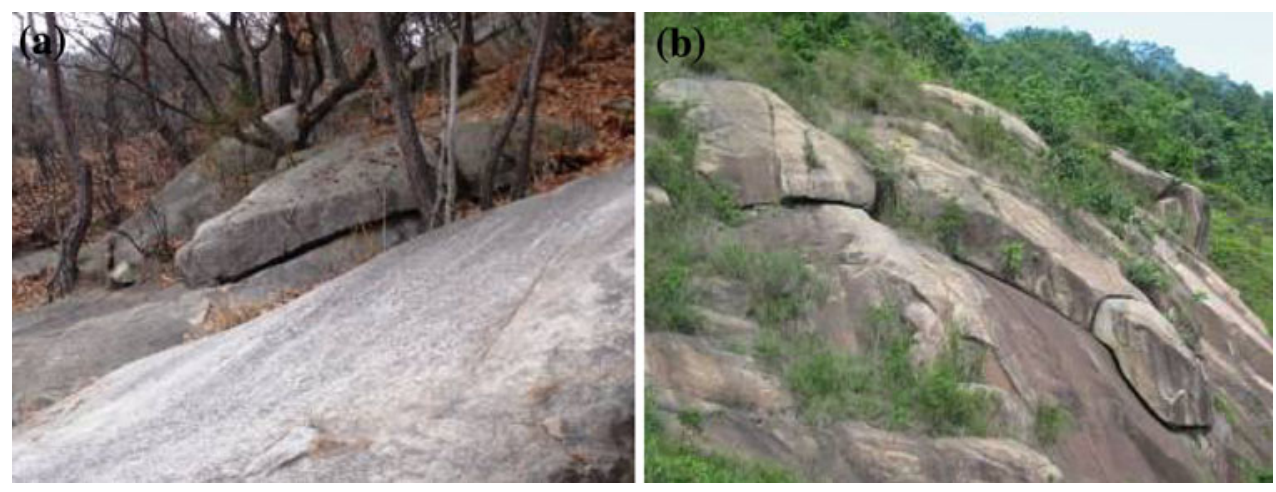
Fig. 12 Storm response of piezometers installed in sheeting joints (after Richards and Cowland 1986)

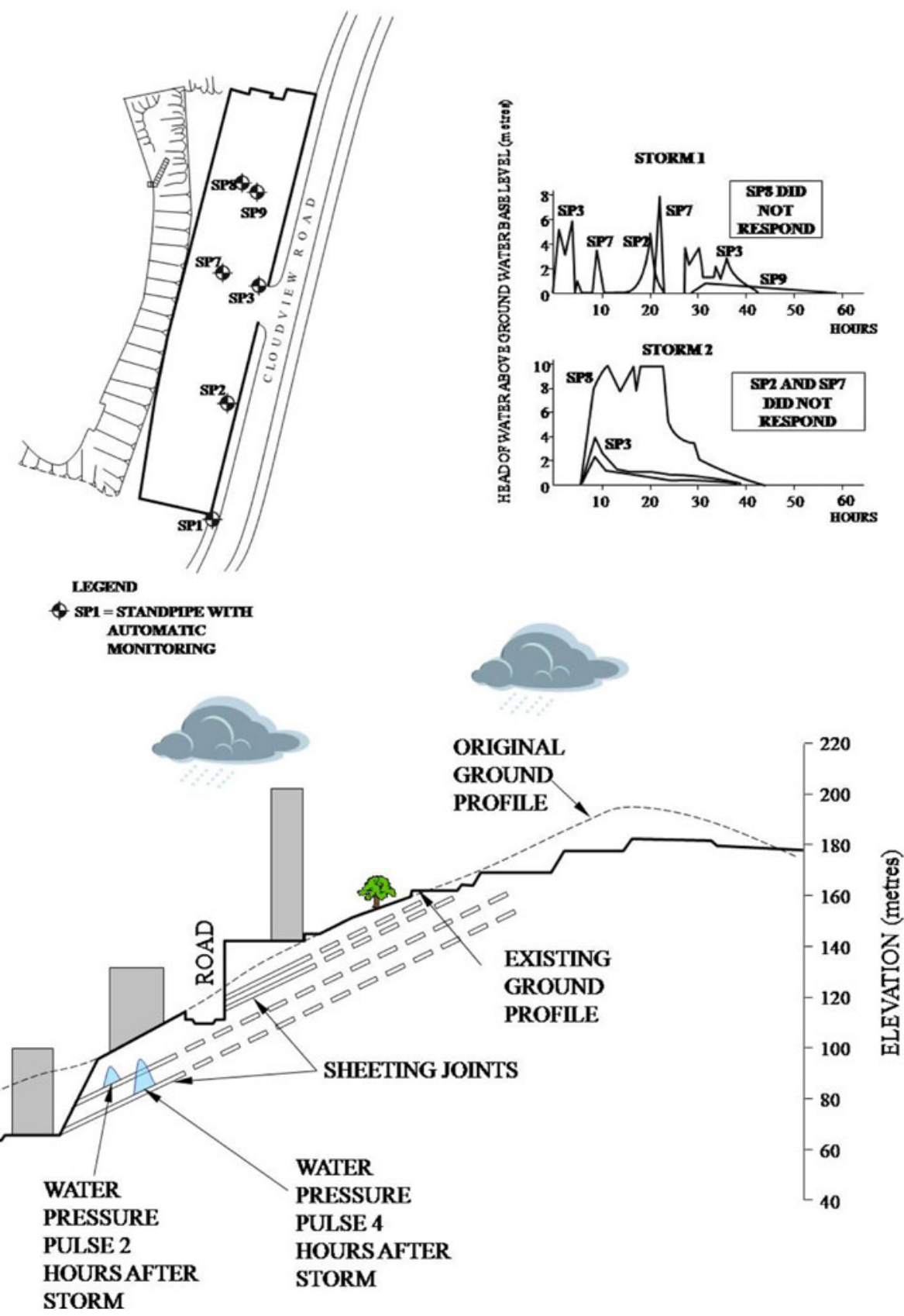

involving two or more joints. The common persistent nature of such joints means that the difficult judgmental issue of the contribution from true cohesion from rock bridges is of minor importance although cohesion might be a real factor for infilled and weathered zones within sheeting joints and for stepped situations where different sections of joint terminate against a pre-existing cross joint. Key factors that always need consideration are geometry (orientation and roughness at all scales), shear strength and the potential for ingress and development of adverse water pressure.

Sheeting joints characteristically are limited to shallow depths and therefore they are subject only to low confining stress. The fact that they tend in most domains to be rough, wavy and often persistent over considerable distances means that they are amenable to rational assessment of shear strength. It is generally agreed that the shear strength of persistent joints can be considered as derived from some "basic" frictional resistance offered by an effectively planar, natural joint plus the work done in overriding the roughness features on that joint. This is generally expressed by the following equation (after Patton 1966):

$\tau=\sigma \tan \left(\phi_{\mathrm{b}}^{\circ}+i^{\circ}\right)$

where $\tau$ is shear strength, $\sigma$ is normal stress, $\phi_{\mathrm{b}}{ }^{\circ}$ is a basic friction angle for a planar joint and $i^{\circ}$ is a dilation angle 
that the centre of gravity of the sliding slab follows during shear, i.e. the deviation from the direction that the shearing would have followed if the plane had been flat and sliding had occurred along the mean dip direction of the joint. Despite the apparent simplicity of the Patton equation, derivation of the parameters can be difficult, especially for judging the effective roughness angle.

\subsection{Basic Friction, $\phi_{\mathrm{b}}$}

Basic friction of natural joints can be measured by direct shear testing but tests need very careful setup, instrumentation and analysis if they are to make sense. A series of tests on different samples of a joint will often yield very wide scatter which is simply not interpretable without correcting for sample-specific dilation as described by Hencher and Richards (1989) and Hencher (1995). Dilation reflects work being done in overriding asperities. The dilation angle, measured during a shear test will vary especially according to the original roughness of the sample and the stress level. It is test-specific, will vary throughout a test and with direction of testing. It is not the same as the dilation angle, $i^{\circ}$, which needs to be assessed at field scale, although the mechanics are the same. To avoid confusion the laboratory-scale dilation angle measured during a test is here designated, $\psi^{\circ}$, whereas the field-scale dilation angle to be judged and allowed for in design is, $i^{\circ}$, as defined by Patton 1966).

Typically, because of the complex nature of shearing, with damage being caused to some roughness asperities whist others are overridden, the dilation angle, $\psi^{\circ}$, is difficult to predict for an irregularly rough sample although numerous efforts have been made to do so with some limited success (e.g. Archambault et al. 1999; Kulatilake et al. 1995). In practice, rather than trying to predict dilation which will be unique to each sample, stress level and testing direction, it is a parameter that needs to be measured carefully during direct shear tests so that corrections can be made to derive a normalised basic friction angle for use in design. Figure 13 shows the result from a well instrumented direct shear test on a rough interlocking joint. It can be seen that the peak measured ratio between shear stress and normal stress $(\tau / \sigma)$ is about 1.4 corresponding to a peak uncorrected friction angle, $\phi_{\mathrm{p}}=54^{\circ}$, given that $\tau=\sigma \tan \left(\phi_{\mathrm{p}}{ }^{\circ}\right)$. This peak strength however includes the effect of the upper block having to override the roughness as the joint dilates and work is done against the confining pressure. The dilation contribution is specific to this sample, this stage of the test, stress level and direction of shearing so cannot be taken as representative or even indicative of the roughness component of the joint, $i^{\circ}$, at field scale. The measured dilation angle, $\psi^{\circ}$ (which equals $\tan ^{-1} \mathrm{dv} / \mathrm{dh}$ where $\mathrm{dv}$ is the vertical displacement

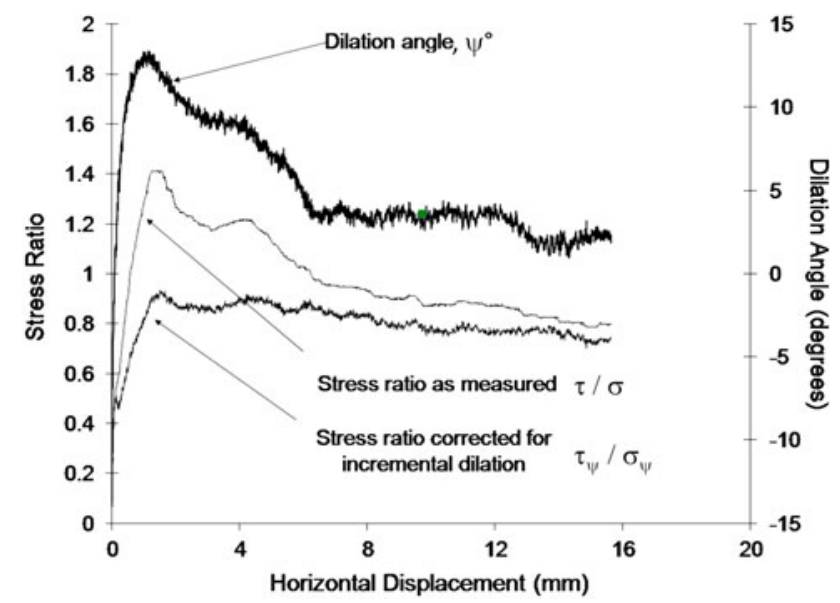

Fig. 13 Typical test from single direct shear test run on a joint sample. Note how the measured strength strongly reflects the incremental dilation angle and how the corrected strength (lower line) is essentially constant once the influence of major, samplespecific roughness has been accounted for

increment over horizontal displacement increment, dh), and which varies throughout the test, can however be used to correct (normalise) the shear strength incrementally using the following equations:

$$
\begin{aligned}
\tau_{\psi} & =(\tau \cos \psi-\sigma \sin \psi) \cos \psi \\
\sigma_{\psi} & =(\sigma \cos \psi-\tau \sin \psi) \cos \psi
\end{aligned}
$$

where $\tau_{\psi}$ and $\sigma_{\psi}$ are the shear and normal stresses corrected for dilation caused by sample roughness. In practice, experience shows that for a system measuring to an accuracy of about $\pm 0.005 \mathrm{~mm}$, analysis over horizontal displacement increments of about $0.2 \mathrm{~mm}$ generally gives reasonably smooth dilation curves whilst retaining most of the detail of the test (Hencher 1995).

In Fig. 13 the maximum dilation angle is about $15^{\circ}$ and occurs slightly earlier than when peak shear strength is measured and then reduces throughout the rest of the test. The ratio between incrementally corrected shear and normal stresses $\left(\tau_{\psi} / \sigma_{\psi}\right)$ peaks at about 0.9 which means a dilation-corrected basic friction angle of about $42^{\circ}\left(\tan ^{-1}\right.$ $0.9)$. The friction angle then reduces gradually over a further $14 \mathrm{~mm}$ horizontal displacement to about $38^{\circ}$ which reflects a reduced textural interlocking and ploughing component together with the production of gouge (Rabinowicz 1965; Scholtz 1990). Tests can be run multi-stage in which the same sample is used for tests at different confining stresses. These test stages generally give the same corrected friction despite the dilation angle changing with stress level and as damage is done to the surfaces. Tests must be properly documented however with photographs, sketches and profiles so that any variable data can be explained rationally (Hencher and Richards 1989). Generally it is found that tests on a series of samples from 
Fig. 14 Series of direct shear tests carried out on three samples taken from different locations along the same joint. Different roughnesses will result in different peak strengths for the same normal stress but dilation correction will reduce scatter considerably and give a basic friction for naturally textured, non-dilatant joints. The same samples can be tested repeatedly at increasing or decreasing normal stress stages. Peak strengths will vary with amount of damage and normal stress level but the corrected strength envelope for basic friction, $\phi_{\mathrm{b}}$, is usually well defined

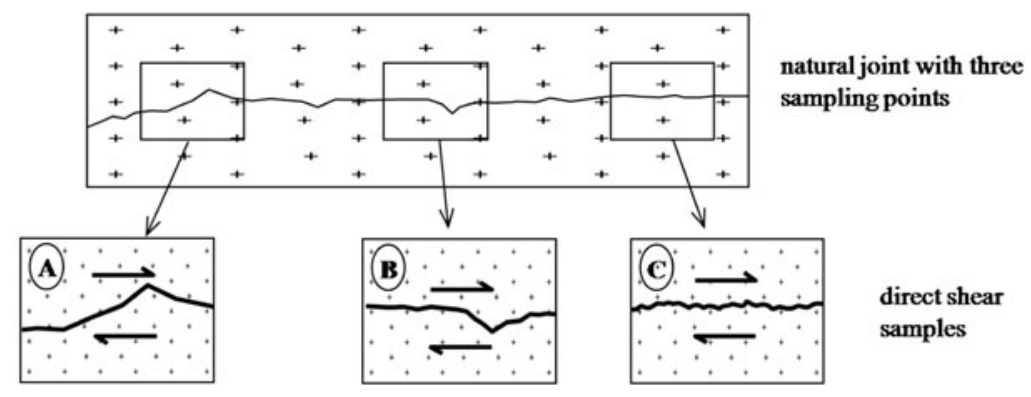

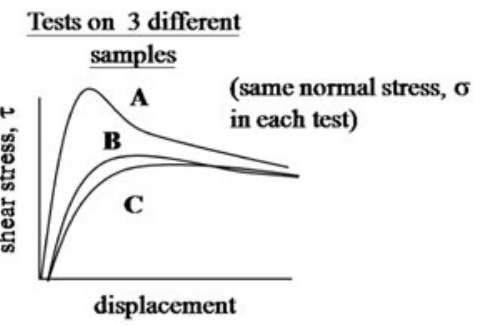

Sample A is roughest and therefore dilates the most and has the highest measured strength

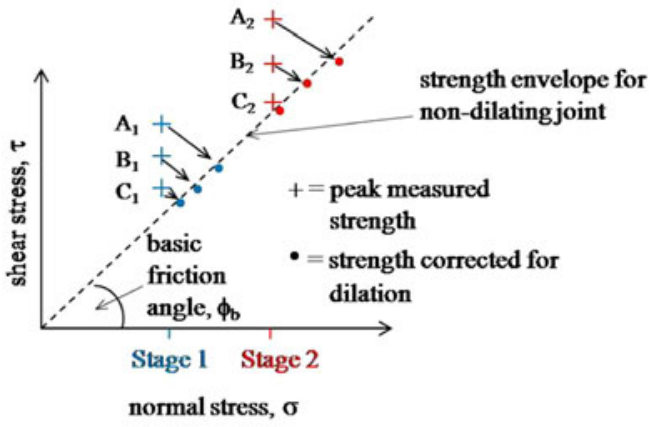

the same joint set (with similar surface mineralogy and textures) provide a reasonably well-defined dilation-corrected strength envelope as illustrated in Fig. 14. That strength is frictional (obeys Amonton's laws) and comprises an adhesional component plus a non-dilational damage component that varies with textural and second order roughness (Hencher 1995).

Barton (1990) suggested that the dilation-corrected basic friction angle might be partly scale-dependent as assumed for the asperity damage component in the Barton-Bandis model (Bandis et al. 1981) but further research using the same shear apparatus and modelling setup as Bandis (1980), but with better instrumentation, indicates that this is unlikely (Hencher et al. 1993; Papaliangas et al. 1994). Rather it appears that the dilation-corrected basic friction, once the effects of small-scale roughness have been corrected for, as described above, remains fairly constant and seemingly independent of the length of the sample. Scale effects do however need to be considered as a geometrical effect when deciding on the appropriate field-scale $i^{\circ}$ value to add to the dilation-corrected $\phi_{\mathrm{b}}$ as discussed below.

This suggested procedure of first testing joints to determine a dilation-corrected basic friction angle and then adding the field-scale roughness angle component is best illustrated by some case examples.

In the early 1980s an extensive series of direct shear tests was conducted on sheeting joints samples taken from drill core as part of the North Point Rock Slope Study in Hong Kong. Samples included strong joints with quartz coating, joints coated with iron and manganese oxides and joints through highly decomposed, grade IV granite
(Hencher and Richards 1982). Figure 15 shows dilationcorrected data for joints through grades II and III granite and Fig. 16 shows similar data for joints through friable, grade IV rock. These data define essentially the same strength envelope with $\phi_{\mathrm{b}} \approx 40^{\circ}$. Similar values for dilation-corrected basic friction angle are reported for other silicate rocks (Papaliangas et al. 1995) and Byerlee (1978) found the same strength envelope $(\tau=0.85 \sigma)$ for a large number of direct shear tests on various rock types where dilation was constrained by using high confining stresses. Similar strengths have been reported as a mean value generally even for more weathered grades IV and V granite in Hong Kong (El-Ramly et al. 2005). Papaliangas et al. 1995 suggest, on the basis of these sort of results, that a friction value of about $40^{\circ}$ for granite joints may mark a transition from dilational to purely frictional behaviour and may relate to a change from brittle to ductile behaviour within highly stressed asperities. Empirically it seems to be about the highest value for basic friction achievable for natural joints through many silicate rocks and applicable specifically to joints that are forced because of small-scale roughness to dilate, which includes most sheeting joints. That said, even higher dilation-corrected values can sometimes be measured for tightly interlocking, rough textured, tensile fractures through very strong rock, at least for several stages of testing (Hencher 1995, 2006). Conversely, it must be remembered that where joints are smoother so that they do not dilate during shear and where the surface texture is fine, polished or coated with low friction minerals such as chlorite, much lower basic friction angles can be measured for natural joints (Brand et al. 


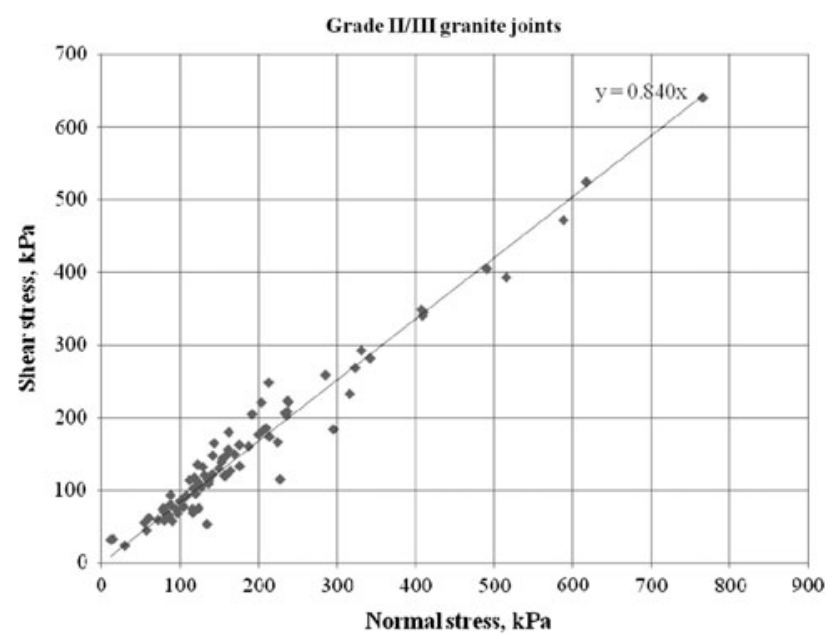

Fig. 15 Dilation-corrected tests on sheeting joint samples through grades II and III rock, many samples iron- or manganese dioxide stained and with some patchy clay

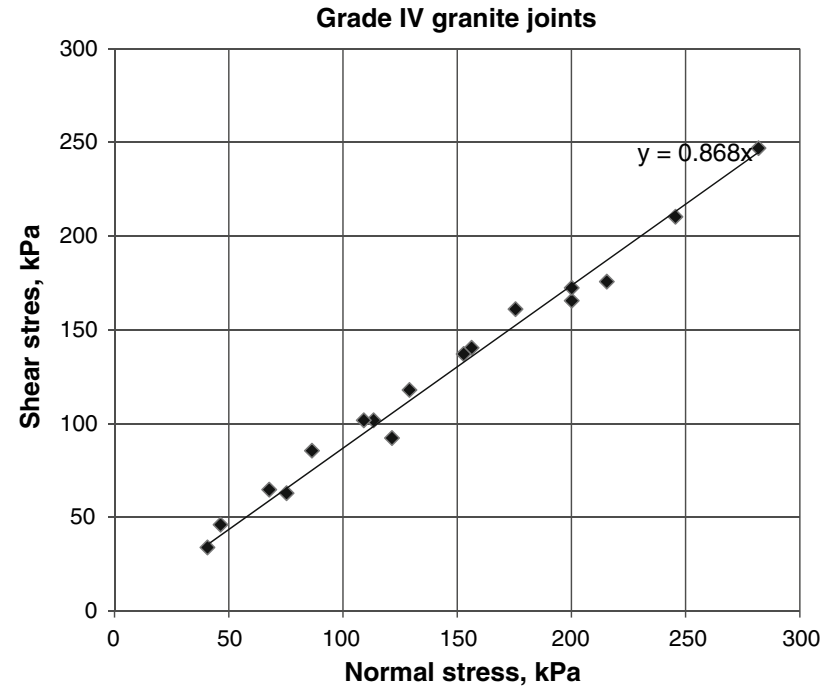

Fig. 16 Dilation corrected data for grade IV material from sheeting joints, North Point, Hong Kong

1983). This means that there is a marked variation between basic friction measured for artificially prepared (saw-cut and lapped) joints and for natural joints with different surface textures, as illustrated in Fig. 17.

\subsection{Roughness}

Roughness at the field scale will be the controlling factor for the stability of most sheeting joints and for engineering design must be added to the basic friction $\phi_{\mathrm{b}}$ of the effectively planar yet naturally surfaced and textured rock joint. Roughness is expressed as an anticipated dilation angle, $i^{\circ}$, which accounts for the likely geometrical path for the sliding slab during failure (deviation from mean dip).
There are two main tasks for the geotechnical engineer in analysing the roughness component for a typical sheeting joint slab failure: firstly, to determine the actual geometry of the surface along the direction of likely sliding at all scales, and secondly, to judge which of those roughness features along the failure path will survive during shear and force the slab to deviate from the mean dip angle. This is the most difficult part of the shear strength assessment, not least because it is impossible to establish the detailed roughness of surfaces that are hidden in the rock mass. Considerable judgement is required and has to be balanced against the risk involved. Hack (1998) gives a good review of the options and the difficulties in exercising engineering judgement are discussed in an insightful way by Baecher and Christian (2003).

In practice, the best way of characterising roughness is by measurement on a grid pattern in the way originally described by Fecker and Rengers (1971) and adopted in the ISRM recommended methods (1978) although spatial variability may be an important issue for sheeting joints; the important first order roughness represented by major wave features may vary considerably from one area to another. At one location a slab might be prevented from sliding by a wave in the joint surface causing a reduction in the effective downdip angle along the sliding direction; elsewhere, a slab of perhaps several metres length may have a dip angle steeper than the mean angle for the joint as a whole because it sits on the down slope section of one of the major waves as illustrated by a case example later. For the Tuen Mun highway stability studies (Carter et al. 2002) numerous true scale survey profiles down the plunge line of exposed sheet structures were collected using EDM surveying techniques, with abseil approaches being utilised to achieve profiles down even the steepest of the slope gradients. These detailed profiles of the exposed surfaces were assumed to be representative of adjacent hidden joints that were candidates for potential failure. The level of roughness/asperity surface detail that is attainable by this sort of survey profiling is illustrated for an extensive discontinuity in Fig. 18.

Defining the scale at which roughness will force dilation during sliding rather than being sheared through requires considerable judgement. Some assistance is provided by Schneider (1976) and by Goodman (1980) who indicate that for typical rough sheeting joint surfaces, where slabs are free to rotate during shear, as the length of the slab increases (at field scale) the dilation angle controlling lifting of the centre of gravity of the upper block will reduce. As noted earlier, sheeting joints are often wavy and major waves, where opposing the shearing direction, can almost always be relied upon to cause dilation at field scale from the mean dip of the overall sheeting joint plane, especially at the low stress levels appropriate for most sheeting joints despite the obvious stress concentrations at 
Fig. 17 Components of basic friction for natural joints and artificial surfaces

\section{Basic Friction of Rock Joints}

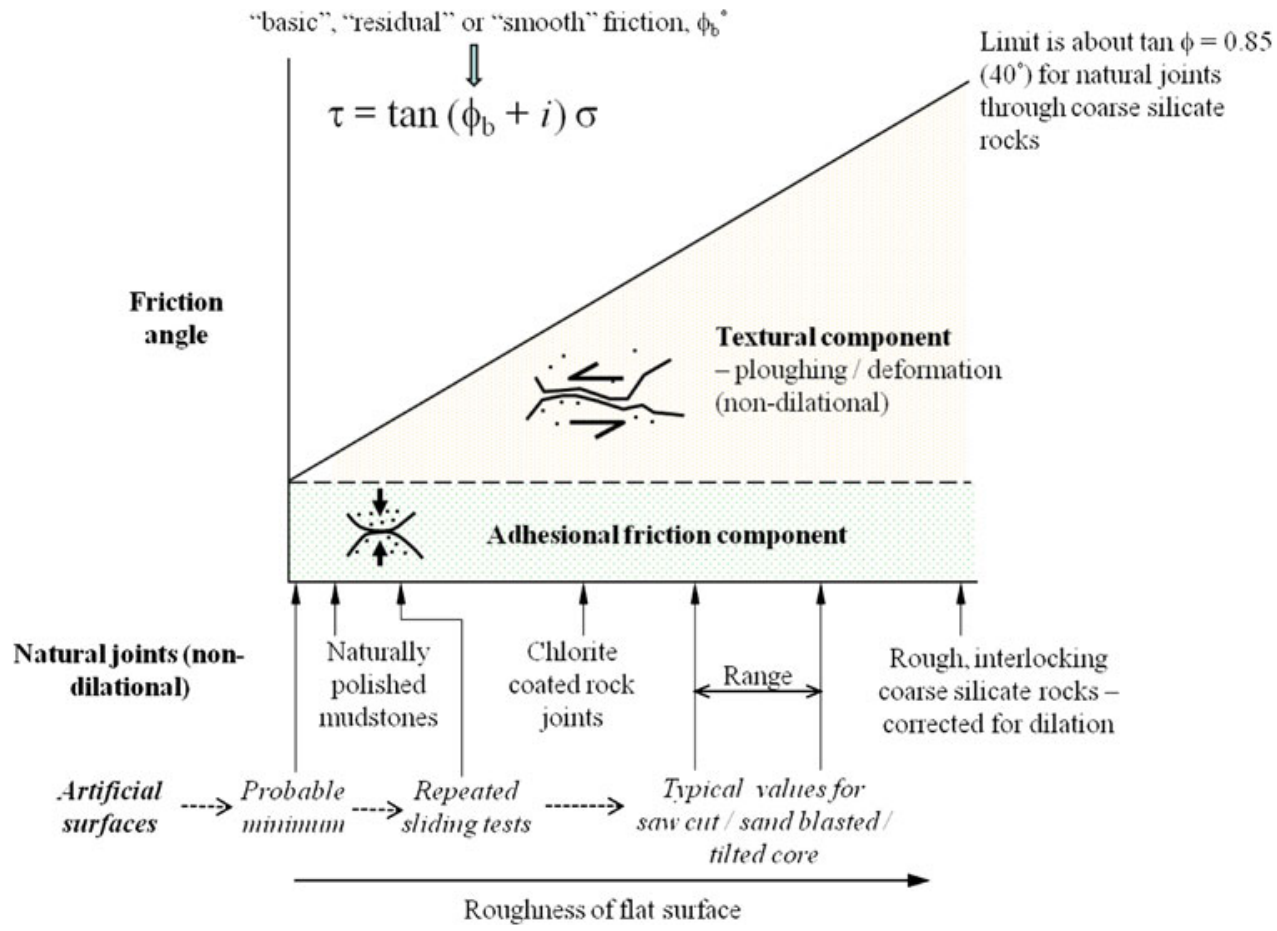

overriding contacts. Simple geometry shows that for wave amplitude of $1 \mathrm{~m}$ over a wavelength of $20 \mathrm{~m}$ the minimum dilation angle would be about $6^{\circ}$; over a wavelengths of $10 \mathrm{~m}, 11^{\circ}$; and over $6 \mathrm{~m}, 18^{\circ}$. This is an example of where geometrical scale effects operate and must be taken into account.

The characterisation of the geometry of sheeting joints in the field is described by Richards and Cowland (1982). Specifically for the North Point Study in Hong Kong it was judged that relatively small base length asperities in grade II and III rock would survive the field stresses based on the observation that little damage occurred to even smaller asperities at stress levels higher than in the field during direct shear tests (e.g. Fig. 19). They therefore concluded that the angle of deviation from mean dip of joints could be relied upon to be $16^{\circ}$ for long sheet joints with lengths of $>20 \mathrm{~m}$, based on the geometry of frequently occurring asperities (they judged that some second order asperity features could be relied upon as well as first order roughnesses). Richards and Cowland (1982) appreciated that the dip of sheeting joints can suddenly steepen on one side of a wave thereby increasing the local dip for a relatively short (few metres) length slab of rock as illustrated by the Hui Ming Street landslide later in this paper. In summary, the issue for differentiating the contribution of small- and large-scale asperities boils down to carrying out appropriate rock characterisation. The problem cannot be finessed by improved analytical methodology. There is no substitution to careful engineering geological inspection,

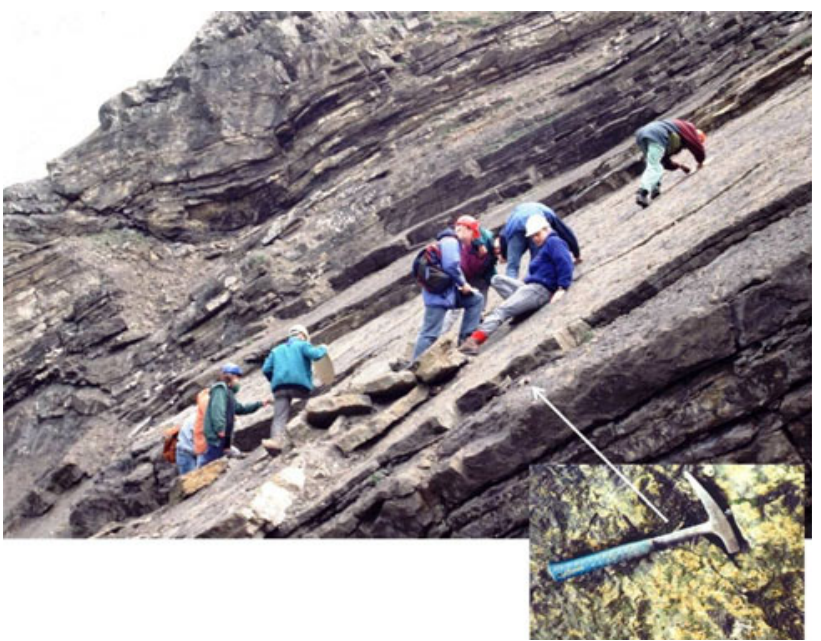

Fig. 18 Roughness survey under way using plates of different diameter on a bedding plane discontinuity in shaley limestone (Skipton, Yorkshire). At the small scale (hammer) the joint is rough but at larger scale the joint is effectively flat

investigation and judgement based on experience of similar joints and geological settings and an appreciation of the fundamental mechanics controlling the potential failure.

\subsection{Infilled Joints}

Richards and Cowland (1982) suggest that where there is a thick band of weathered rock along a joint (say grades IV and V) as shown in Fig. 5, zero dilation should be allowed 


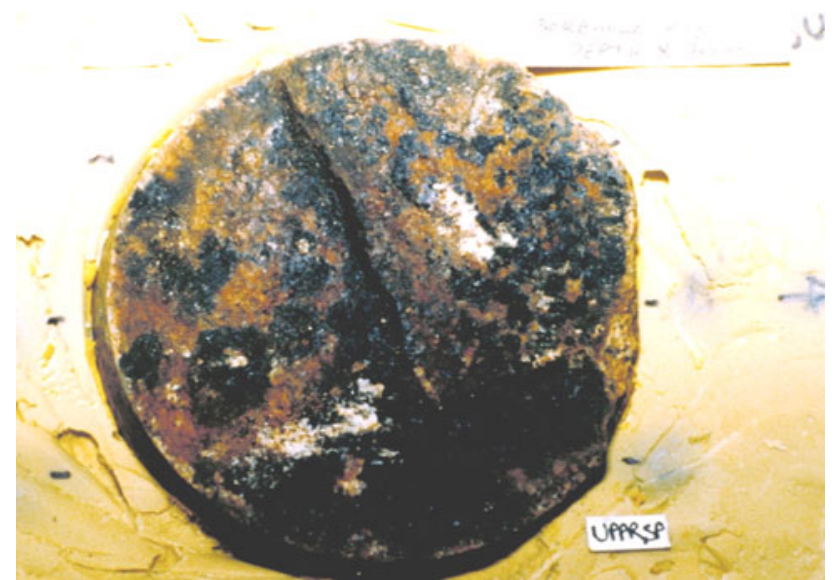

Fig. 19 Sample V13, $8.7 \mathrm{~m}$ (North Point Study, Hong Kong) following 5 stage, repeated direct shear test up to normal stress $285 \mathrm{kPa}$ equivalent of more than $10 \mathrm{~m}$ confining stress. Note the localised nature of damage (white areas) on the weathered, stepped surface coated in brown iron and black manganese dioxide. Note that main step feature has survived intact (and was responsible for dilating the joint) at that stress level

when assessing stability. Where the joint is infilled with a mixture of weathered rock and rock fragments however the Hoek-Brown strength criterion might be used to provide some estimate of strength without laboratory testing (Carter et al. 2002) although Brown (2008) cautions against applying the original criterion outside the original data set and expresses specific concern for application for rocks with uniaxial compressive strength (UCS) below about 30 or $40 \mathrm{MPa}$. Carter et al. (2008) and Carvalho et al. (2007) discuss a modified Hoek-Brown criterion for low strength rocks that may be more applicable for such application.

As discussed earlier, incremental movement of sheeting joints may take place over many years before final slab detachment and, following each movement, sediment may be washed in to accumulate in hollows on the joint (Fig. 20). The presence of washed-in sediment may indicate that the rock mass has moved but this is not always the case as illustrated by a case at Kwun Tong Road, Hong Kong, discussed later, where the observed sediments were deposited in an erosional pipe along a sheeting joint rather than in a void opened up by dilation. The presence of inwashed sediment in a joint might cause alarm during ground investigation (clay infill having relatively low shear strength) but in many cases such sediments are patchy in occurrence and confined to local down warps on a partially dilated joint. The sediment is probably playing little or no part in decreasing frictional resistance which is controlled by contact between rock asperities. When the infill becomes of such thickness that rock wall contact is no longer to be relied upon then of course the infill strength itself needs to be assessed for design. The infill will also affect hydraulic conductivity properties of such infilled

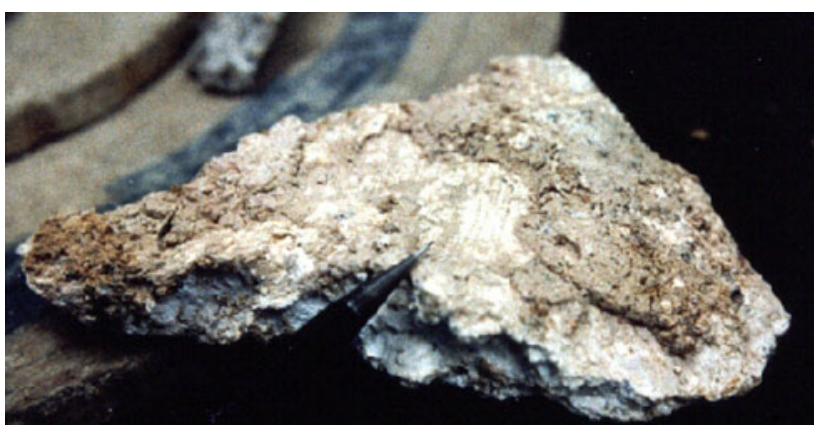

Fig. 20 Hard, slickensided kaolinite infill from downwarp on failed sheeting joint (Hencher 1983). Pencil for scale

joints and particularly will affect pore pressure dissipation rates, potentially leading to an adverse stability state due to the potential for a lengthened period of reduced effective stress following a rain storm event. Experience from the piezometric monitoring of "infilled" and of "clean" sheeting joints at Tuen Mun (Carter et al. 2002) showed that although similar maximum pore pressure spike levels were recorded for both joint types, it took days instead of hours for the dissipation of the excess head in the filled joints compared with the clean joints.

\subsection{Estimating Shear Strength Using Empirical Methods}

Because of the inherent difficulties, need for quality equipment and expertise required for measuring shear strength of rock joints, various empirical criteria have been proposed for estimating shear strength based on index tests and idealised joint shapes. The most widely used strength criterion is that proposed by Barton (1973). This takes the "basic friction" measured for saw-cut or other artificially prepared planar surfaces then adding in a component to account for roughness adjusted for the strength of the rock asperities and for scale. Details are given in many text books including Brady and Brown (1985) and Wyllie and Mah (2004). The advantages of this criterion are its apparent ease of use and application in numerical modelling but there are difficulties in determining each of the various parameters. Basic friction is taken to be a lower bound component with a "limiting value" of 28.5-31.5 (Barton and Bandis 1990) but the friction measured for a saw-cut surface is not necessarily a lower bound either for natural or artificial joints (see Fig. 17). Hencher (1976) for example reports the sliding angle reducing from about $32^{\circ}$ to only $12^{\circ}$ for saw-cut surfaces of Darleydale Sandstone after about $4 \mathrm{~m}$ in tilt tests with continual removal of rock flour between test runs. Furthermore, considerable variability is sometimes reported from tests carried out on artificially prepared surfaces. Stimpson (1981) measured 
values ranging from $24^{\circ}$ to $38^{\circ}$ using limestone core pieces in sliding tests. Tests reported by the Norwegian Geotechnical Institute (NGI) for the Aknes landslide investigation gave values ranging from $21^{\circ}$ to $36.4^{\circ}$ for tilt tests on saw-cut joints with about $73 \%$ of data between $25^{\circ}$ and $30.2^{\circ}$ (Kveldsvik et al. 2008). Nicholson (1994) reports a variation in $12.5^{\circ}$ for tests carried out on carefully prepared saw-cut, lapped surfaces of Berea sandstone, all suggesting that the recommendation of some lower "limiting value" of 28.5 to $31.5^{\circ}$ may not be universally applicable. There is also some confusion in the literature regarding application of some of the Barton early equations as to whether $\phi_{\mathrm{b}}$ (which is stipulated as sawn surface value determinations) or $\phi_{\mathrm{r}}$ (residual values from multi-reversal shear box testing) is the appropriate parameter for application in the equation. In the authors' opinion is also extremely unwise to rely on the widely publicised Schmidt Hammer relationships proposed between residual strength and base friction angle as a means for sorting out the correct value for shear strength determination.

The contribution to shear strength from roughness for small-scale roughness can be measured or estimated from standard shape profiles, but this can be difficult in practice and varies according to shearing direction and with scale, requiring appropriate judgement for its effective application. Beer et al. (2002) carried out an online survey of people's estimates of joint roughness coefficient (JRC) for three randomly selected joints. Considerable scatter was reported and for one of the three joints a possibly bi-modal distribution of estimates was determined with the two centres of population at 8.9 and 17.9 , perhaps reflecting different individual's perception of controlling roughness scale. Like any other stochastic parameter, considerable difficulties can occur when representing joint roughness with a single value JRC estimate, as clearly demonstrated by determinations for the Aknes landslide by workers from NGI and MIT (Kveldsvik et al. 2008) where JRC measured for foliation joints at a $0.25-\mathrm{m}$ scale ranged from 2.5 to 20 with a mean of 10.6. At a 1-m scale, JRC estimates covered the full possible range (from 0 to 20) with a mean of about 8 and standard deviation of $\sim 4$. The range of calculated factor of safety for this range of JRC was from about 0.8-2.0 taking all other parameters at their mean values. As is obvious, considerable judgement is still needed in application of such empirical procedures so that overall estimates for joint surface strength can be considered realistic. Furthermore, once the second order roughness contribution has been decided upon, then an additional roughness angle, $i^{\circ}$, still needs to be determined and added, to account for larger scale roughness not sampled in the JRC assessment (Barton 1990).

An important point that arises from this review of empirical strength criteria for estimating field strength of rock joints is that it needs to be emphasised that the correct base-line parameters must be utilised within the equations whatever approach is adopted. It is a prevalent misconception in the literature (e.g. Simons et al. 2001) that dilation-corrected data from direct shear tests on natural joints can be used interchangeably in empirical equations. This is incorrect because the dilation-corrected strength already includes a frictional component contributed from textural and roughness damage (part equivalent of JRC) and its substitution for the saw-cut or residual $\phi_{\mathrm{b}}$ of Barton could lead to overestimations of field-scale strength by maybe $10^{\circ}$ in many cases.

\section{Case Examples of Landslides Involving Sheeting Joints}

A number of landslides involving sliding on sheeting joints have been studied in some detail in Hong Kong and provide some insight into operative shear strength and mechanisms of failure.

\subsection{Sau Mau Ping Road, Hong Kong, Early 1970s}

An example of an in-depth study of slope stability governed by potential sliding on sheeting joint is presented by Hoek (2009) and Wyllie and Mah (2004). Figure 21a shows a section of the slope as it is today, little changed from the slope photographed in the early 1970s, with an extensive section of exposed sheeting joint following a failure during blasting to construct the road. It was anticipated that the exposed sheeting joint would extend through the adjacent $60-\mathrm{m}$-high slope with an overall angle of $50^{\circ}$ and individual batters $20 \mathrm{~m}$ high and inclined at $70^{\circ}$. The slope that was of concern has now been cut back as illustrated in Fig. 21b (compare to Hoek's Fig. 4). Hoek goes through a reasoned series of sensitivity calculations based on various assumptions, culminating in the decision to cut back rather than drain or reinforce the slope. The interpretation at the time was that the additional strength offered by dilation in overcoming roughness could be expressed as apparent cohesion. If these analyses and calculations were repeated today probably a slightly different approach would be taken in the way that shear strength was dealt with and consequently on the measures adopted. In particular a cohesive component of strength is insensitive to water pressure assumptions, whereas if strength is expressed as friction plus dilation angle, both of these are dependent on effective stress and a different answer would ensue. Apparent cohesion is clearly a good concept for jointed rock masses (e.g. Brown 2008) but not for the shear strength of persistent rock joints. The result and conclusions might still be the same (cutting back the slope to the dip angle of the sheeting joint is certainly a pragmatic 


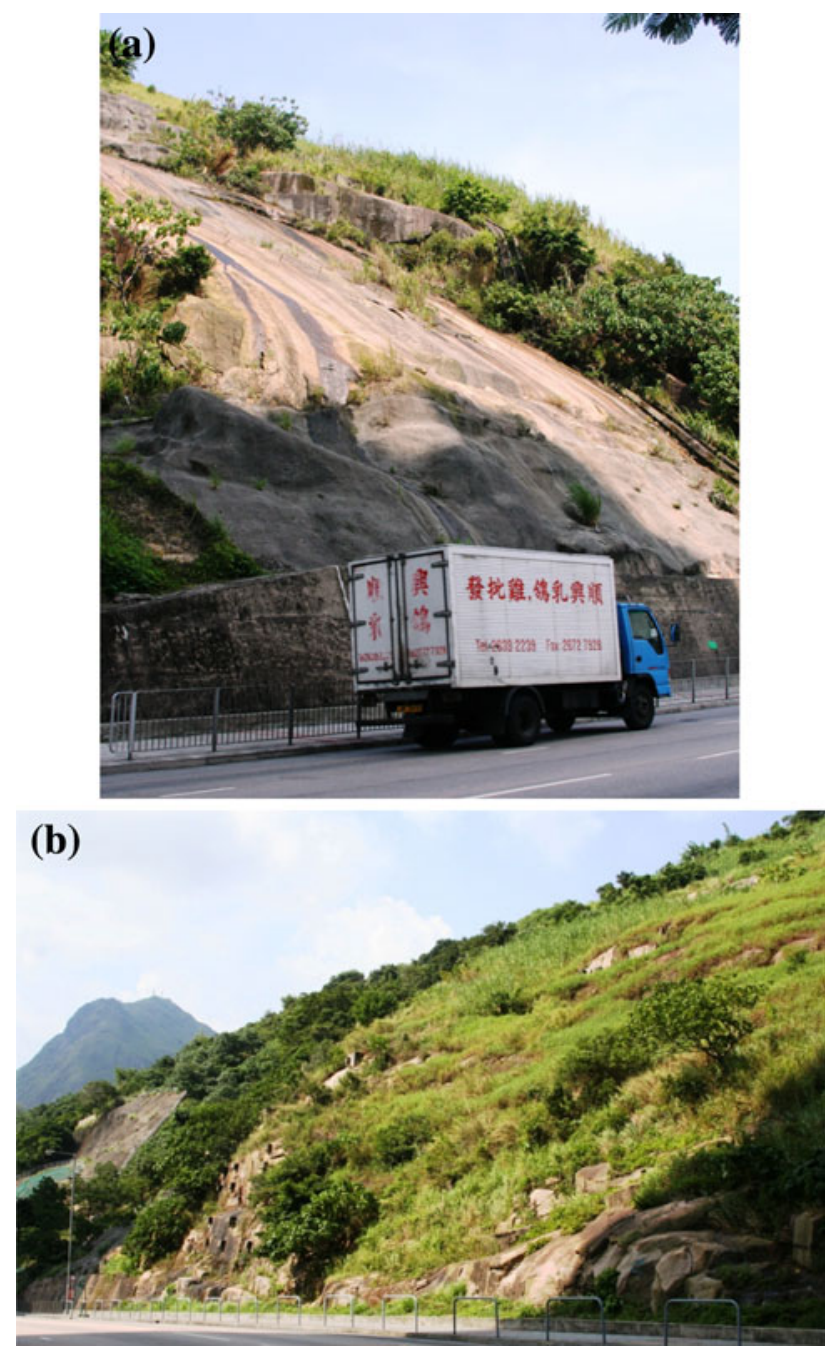

Fig. 21 a View of sheeting joint (2007) pictured in Hoek (2009); b picture of the slope analysed and then cut back as discussed in detail in Hoek (2009)

solution) but the assessment approach might well now be different.

\subsection{Hui Ming Street 2000 and 1993}

In 2000 a block of rock with volume of $15 \mathrm{~m}^{3}$ fell close to a playground after sliding on a sheeting joint. The source of the rock fall is shown in Fig. 22. A nearby previous failure of a 20-m-wide section of slope in 1993 was re-examined as part of the study into the 2000 landslide Halcrow China Ltd (2002a). The basal surface of the 2000 rockfall dipped out of the slope at about $35^{\circ}-38^{\circ}$. Using a $420-\mathrm{mm}$ diameter plate on a 200 -mm grid across the failure surface a dilation angle, $i^{\circ}$ of $8^{\circ}$, was determined and for an $80-\mathrm{mm}$ plate, between $12^{\circ}$ and $14^{\circ}$ which is consistent with measurements on other sheeting joints in Hong Kong. The section of sheeting joint below the failed block that would have been exposed prior to failure, dipped more shallowly

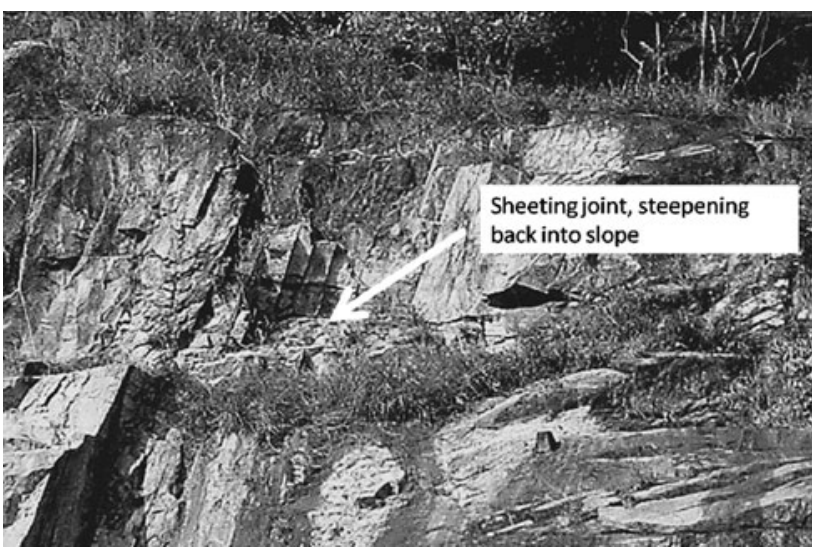

Fig. 22 Location of rock fall at Hui Min Street, 2000

at less than $30^{\circ}$. This case illustrates that significant block failures can occur on unexposed steep sections of sheeting joint. Back analysis showed that for an effective friction angle $\left(\phi_{\mathrm{b}}+i\right)$ of $43^{\circ}$ the factor of safety was 1.2 under dry conditions and reduced to 1.0 with water pressure of about $10 \mathrm{kPa}$. The nearby, much larger 1993 failure surface was investigated by cutting trial trenches through shotcrete that had been placed over the landslide scar. The mean dip of the lower part of the failure surface was only about $22^{\circ}$ but steepened to about $45^{\circ}$ over the rear half of the failure surface. Roughness values (deviation from mean dip) were measured as $16^{\circ}$ using an $80-\mathrm{mm}$ plate and $12^{\circ}$ for a 210 $\mathrm{mm}$ plate. Much of the basal surface was however coated with completely and highly decomposed granite which would have reduced the effective dilation angle.

\subsection{Above Leung King Estate: 2000}

The progressive nature of failures associated with sheeting joints is illustrated well by a landslide that occurred above Leung King Estate, Hong Kong (Halcrow China Limited 2002b; Hencher 2006). Features of this landslide are illustrated in Fig. 23. Surviving remnants of the rock mass above the main sheeting joint along which detachment finally took place showed signs of long-term movement, growth of fractures and sediment infill prior to failure. The stages prior to failure are shown schematically in Fig. 24 .

\subsection{Lessons from Landslide Case Studies}

These case examples of landslides involving sliding on sheeting joints have provided some useful insights into the nature and characteristics of such failures. In particular, the failure above Leung King Estate gave considerable evidence of long-term deterioration involving intermittent movements by sliding along the joint along which detachment eventually occurred. Such deterioration with sediment infill and natural pipe systems may be taken as indications 
Fig. 23 Landslide above Leung King Estate, Hong Kong. a Below the detachment surface the rock is light coloured and joints are rare; above, the rock is fractured and discoloured.

b Lower wavy surface with grid for roughness measurements using plates. c Side view with evidence of long-term displacement including dilation and deposition of sediments in voids
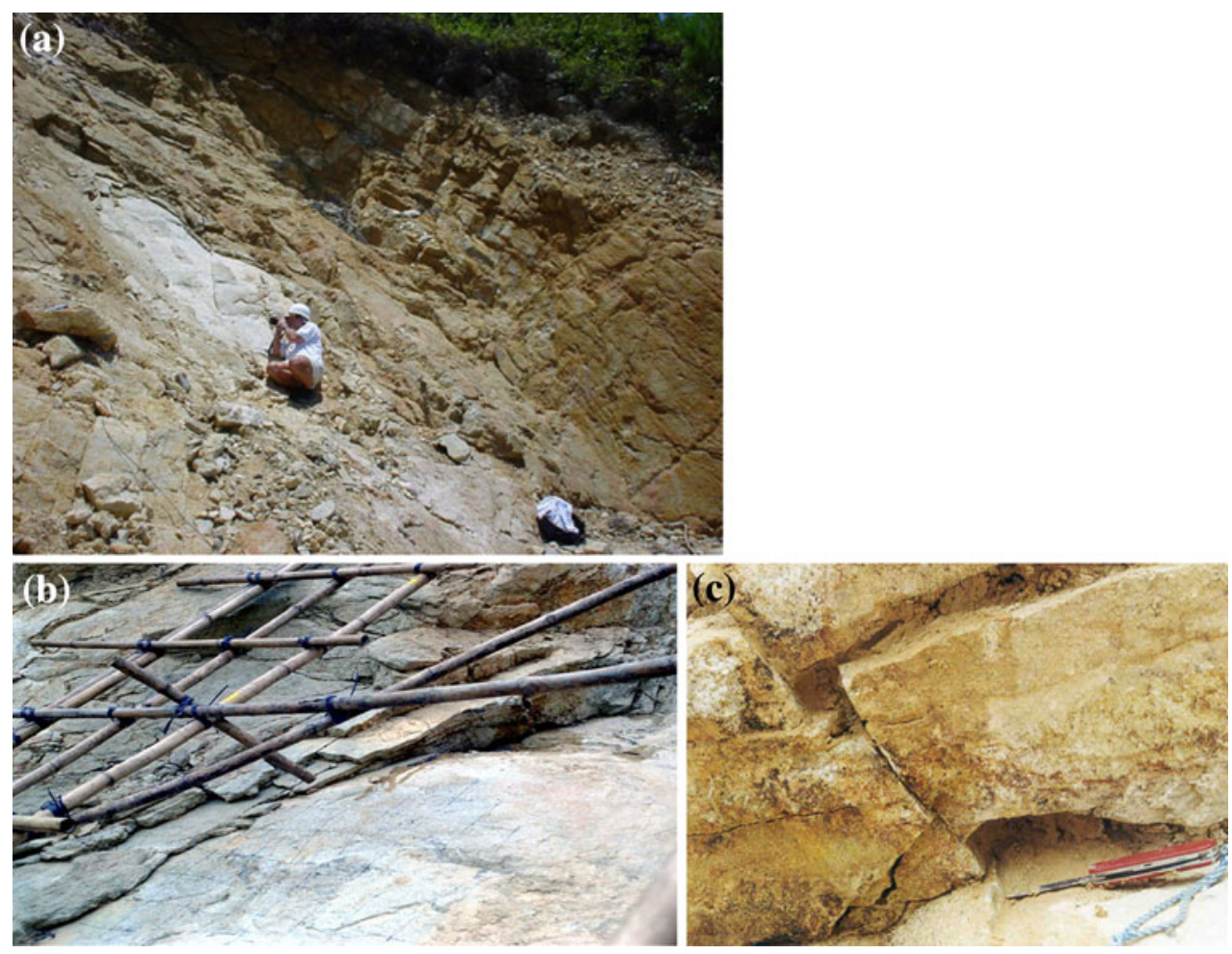

1.

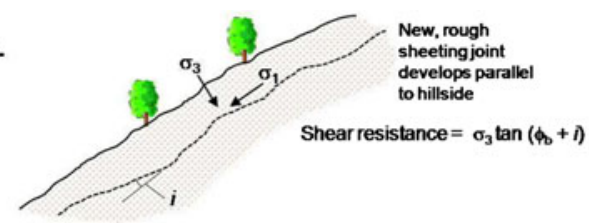

2.

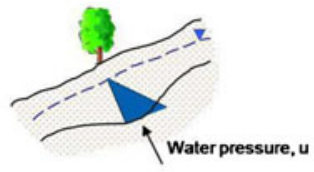

- Following heavy rainfall water pressure develops in fracture Shear resistance reduces to $\left(\sigma_{3}-u\right) \tan \left(\phi_{0}+i\right)$ Movement initiated

3.

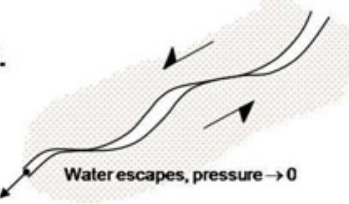

- Joint dilates during movement Permeability increases - Water pressure drops - Movementceases

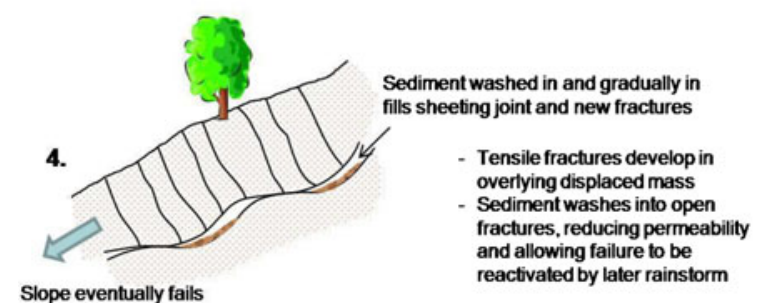

Fig. 24 Schematic representation of history of Leung King landslide prior to detachment that the slope may be failing. The importance of the development of cleft water pressure is evident in triggering most sheeting joint failures investigated in Hong Kong. The ground investigation reported by Richards and Cowland (1986) which demonstrated the complex reaction of water pressures in joints to rainstorm events indicates the difficulties in designing drainage measures to prevent failure.

The case studies demonstrate the difficulties in extrapolating the geometry of sheeting joints into the rock mass from measurements in exposures. In particular local increases in dip hidden in the rock mass can allow significant and unpredicted rock falls.

Back analysis of landslides adopting reasonable estimates for active water pressures confirms that the current approaches to assessing shear strength based on dilationcorrected basic friction plus an $i^{\circ}$ value judged from roughness measurements on a grid basis at field scale can provide realistic parameters for design use.

\section{Engineering Works}

\subsection{Assessing Risk and the Need for Preventive Engineering Measures}

Slopes in sheeting joint terrain often appear extremely threatening because of the persistent, daylighting and 
steeply dipping nature of the joints. The fact that such steeply dipping joints are associated with failures at all scales from small rock falls to major translational movements has, over the years, necessitated that engineering works be implemented to reduce the risks.

A modern approach to assessing the need for preventive measures is to use quantified risk assessment as described by Pine and Roberds (2005) for the widening of the Tuen Mun Highway in Hong Kong (Fig. 1b). This project involved remediation and stabilisation of several sections of high cut and natural slopes dominated by potential sheeting joint failures and by the potential for failure of rock blocks and boulders bouncing down exposed sheeting joints to impact the road below. Design of the slope cut backs and stabilisation measures was based on a combination of reliability criteria and conventional Hong Kong standard factor of safety design targets aimed at achieving an ALARP (as low as reasonably possible) risk target which, in actuarial terms, translated to less than 0.01 fatalities per year per $500 \mathrm{~m}$ section of the slopes under remediation.

\subsection{General Considerations}

Remediation of sheeting joint-controlled stability hazards on high rock slopes is often not trivial and implementation of the works can itself increase the risk levels albeit temporarily. Factors that will influence the decision on which measures to implement include the specific nature of the hazards, topographic and access constraints, locations of the facilities at risk, cost and timing. The risks associated with carrying out works next to active roads both to road users and to construction workers themselves and how to mitigate these are addressed in some detail in Geotechnical Engineering Office (2000a) and Halcrow China Limited (2002c). Pre-contract stabilisation works will often be needed to allow initial site access and preparation. Preventive measures such as rock bolting may be carried out at an early stage to assist in the safe working of the site and designed to form part of the permanent works. Options for the use of protective barriers and catch nets to minimise disruption to traffic during the works also need to be addressed, as do contractual controls and alternatives for supervision of the works. The use of a risk register, as piloted for tunnels (Brown 1999), with clear identification of particular risks and responsible parties, helps to ensure that all hazards and consequences are adequately dealt with during construction. Decision analysis is now widely applied at an early stage to assess whether to mitigate slope hazards (e.g. by rockfall catch nets) or to remediate/resolve the problem by excavation and/or support approaches. If construction of intrusive engineering measures to stabilise hazards might be unduly risky, then passive protection can be adopted instead. A hybrid solution is often the most pragmatic solution for extensive, difficult slopes such as at Tuen Mun Road where some sections were stabilised by anchors and buttresses and other sections were protected by nets and other measures (Carter et al. 2002; Pine and Roberds 2005).

\section{Engineering Options}

Some of the options for improving the stability of slopes are listed in Fig. 25 and illustrated in Fig. 26. These can be split into passive options that either deal with the possible failure by controlling surface deterioration at source or installing preventative reinforcement to increase local factors of safety, or adding walls or buttresses to restrain detached debris before it causes injury or damage and active measures that enhance overall factors of safety of larger sections of slope by major engineering works including cut backs or buttresses or heavy tie-back cabling.

\subsection{Surface Treatment}

Many risks can be mitigated through surface treatment to stabilise or remove relatively small blocks of rock. There is a temptation to use hard slope treatments like chunam (old

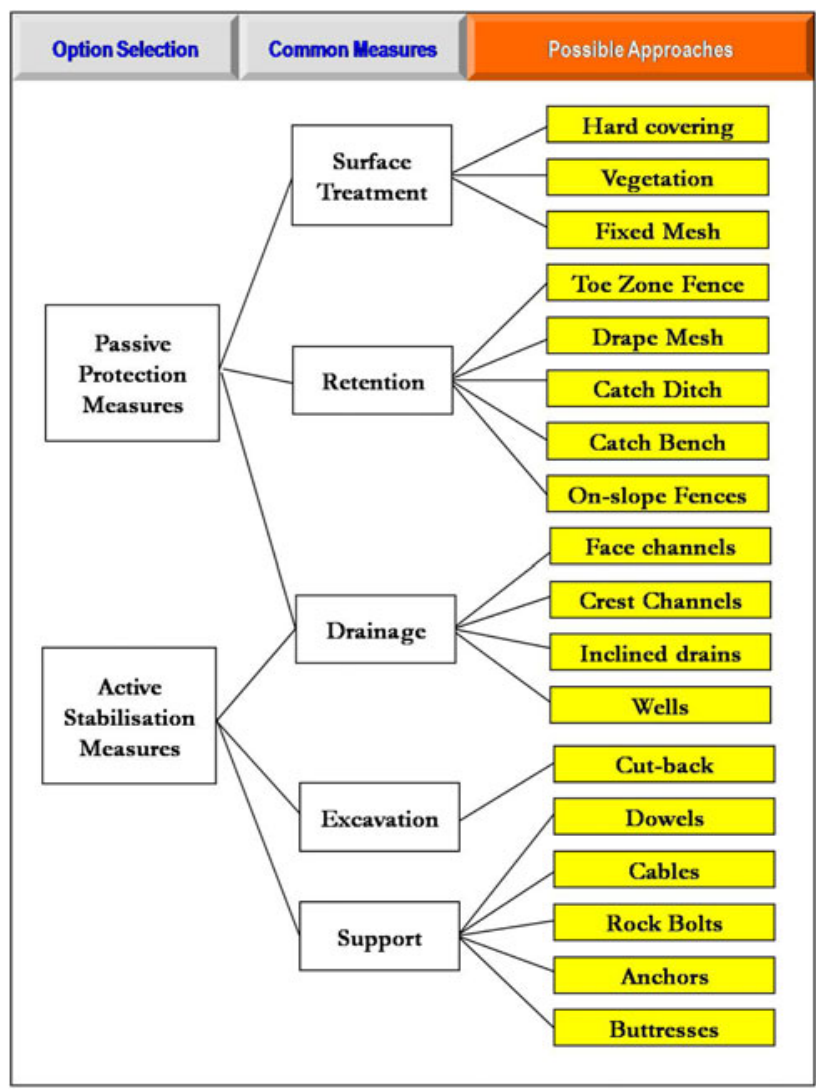

Fig. 25 Engineering options for stabilising slopes in sheeting joint terrain 


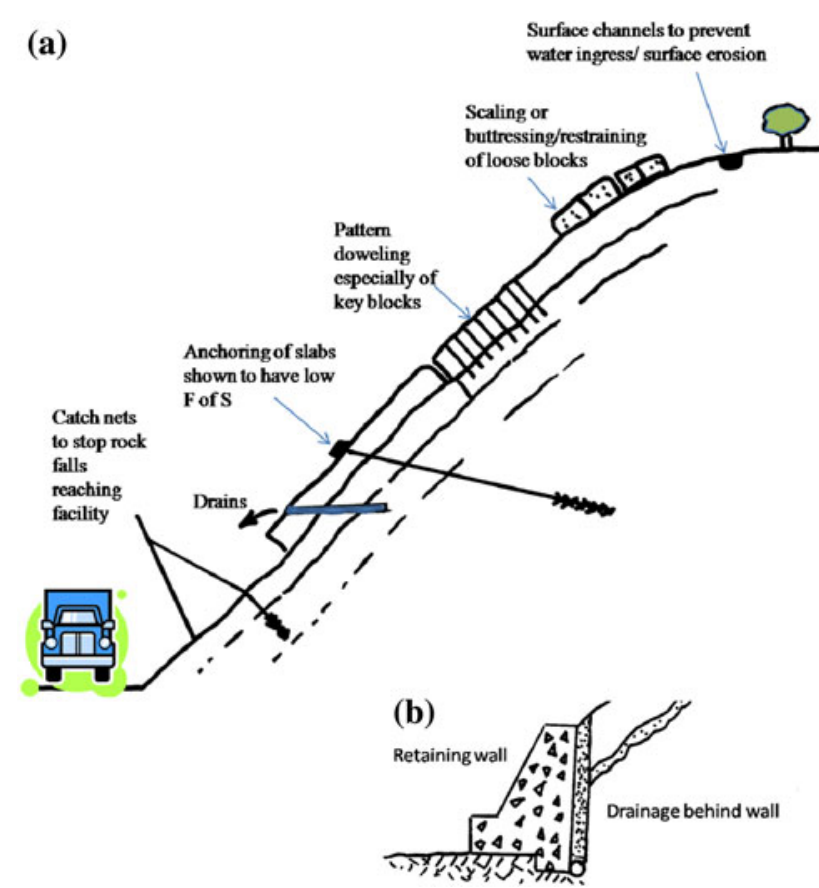

Fig. 26 a Main engineering options for stabilising slopes in sheeting joint terrain; b retaining wall used to buttress large section of slope

HK remedy) and shotcrete to constrain loose blocks at the slope surface but such measures if not properly designed can restrict drainage from the slope, hide the geological situation from future investigators and can themselves cause a hazard as the shotcrete deteriorates allowing large slabs of shotcrete to detach and impact whoever is unfortunate enough to be below (Fig. 27). Furthermore, shotcrete is increasingly an unacceptable solution for aesthetic reasons and there is a push towards landscaping high, visual slopes where measures can be justified from an engineering sense (Geotechnical Engineering Office 2000b). In this context it is to be noted that most bioengineering solutions will not work for high-risk slopes in that they cannot be relied upon in the long-term and root growth can lead to blocks becoming loosened and detached. Where individual rock fall sources are identified, these can be scaled off, reinforced by dowels, bolts, cables or dentition and/or netted where the rock is in a closely jointed state. Removing large blocks can be difficult because of the inherent risks associated with breakage techniques including blasting and chemical splitting which can dislodge blocks unexpectedly. Care must be taken to protect the public and workers during such operations. The most difficult zones to deal with are those with poor access. Implementing passive or active protection approaches needs to start from safe ground and move progressively into the areas of more hazardous stability.

Rockfall trajectory analysis using widely available software allows prediction of energy requirements and

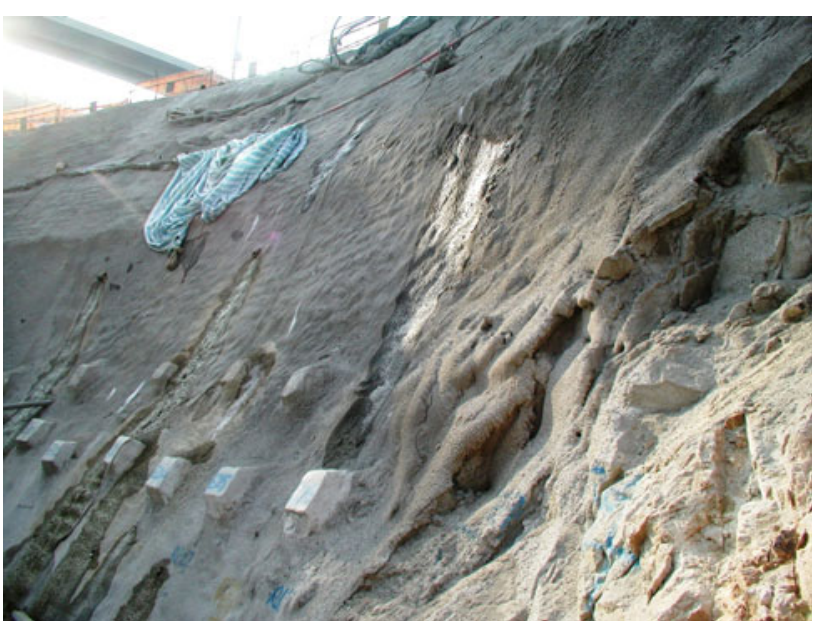

Fig. 27 Use of shotcrete on broken rock face together with anchorages (nails). Disadvantages include damming water, hiding what is going on and the shotcrete itself will form a hazard as it deteriorates

likely bounce heights and run-out damage zone extent. Where energy considerations allow, toe-zone protection measures, catch benches, catch ditches, and toe fences provide the earliest viable mitigation approach without requiring access on the slope.

Surface drainage is a very important consideration for all slopes but particularly for slopes comprising part rock (with very high runoff) and soil sections which might be eroded and undermined from high surface flow concentration.

\subsection{Mesh Drapes}

Where slope heights are significant and ramp or bench approach is difficult, mitigating hazards can be problematic even using rope access techniques because face stability may be too unstable to even allow rock climbing personnel onto the face. Under such conditions surface mesh draping may allow some effective protection to be achieved preventing ski jump-style bouncing of rock progressively down slope (Carter et al. 2002). Application of drape mesh (varying from chain-link, triple twist, hex-mesh to ring-net in increasing order of energy capacity) can be effected by a variety of techniques ranging from climber controlled unrolling of the mesh to helicopter access placement. Typically, crest restraint is provided by dowels or tie-back anchors usually cabled back some distance from the crest zone to provide a safe anchorage.

\subsection{Fences, Catch Nets and Barriers}

Where there is the potential for repeated small-scale detachments impacting a highway, then catch nets or diversion/stopping barriers can be the solution as discussed 
with reference to reducing risk by Pine and Roberds (2005). Such catch nets or fences can be positioned onslope as illustrated in Fig. 28 (from Carter et al. 2002) or in the toe zone of the slope depending on energy requirements and site restrictions. Where energies computed from rockfall analyses are too extreme for toe-zone protection alone to maintain risk levels below prescribed criteria for highway users, on-slope energy protection fences become a necessity to reduce total energy impact at road level. This was the approach adopted at Tuen Mun Road in Hong Kong for sections of the slopes which were to remain in place and where sheeting joint geometries were considered hazardous enough to allow potential release of blocks of sizes that could not be stopped by toe-zone fencing alone. The photograph in Fig. 28 shows an on-slope 3,000 kJ fence designed and installed above the highway to catch rockfall blocks from the $100 \mathrm{~m}$ of slope upslope of the fence. This fence is located about $80 \mathrm{~m}$ vertically above the main carriageway of the highway, where the main toe-zone fence and catch ditch are located.

\subsection{Drainage}

Drainage can be very effective in preventing the development of adverse water pressures, but there is a need to target subsurface flow channels many of which will be shallow and ephemeral. The paths may be tortuous and hard to identify and drainage measures can therefore be rather hit or miss (Hencher 2010). Regular patterns of long horizontal drain holes can be very effective, but it must never be expected that all drains will yield water flows and

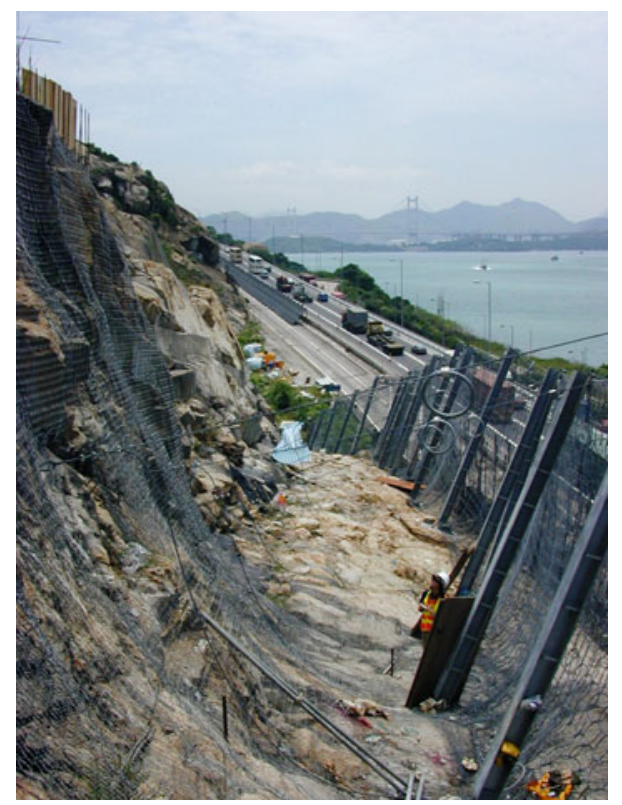

Fig. 28 Catch net to stop rock falls, above Tuen Mun Highway, Hong Kong the effectiveness of individual drains can change with time as subsurface flow paths migrate. With exposed sheeting joints forming ledges on a slope, care must be taken that the step zones are not shotcreted otherwise free drainage may be impeded and water might dam up behind the shotcrete. If the exposed joint is weathered the weak material may back-sap and possibly pipe leading to destabilisation, partially caused by lack of free drainage. This can be rectified by installing closely spaced horizontal drains with geotextile filter fabric sleeves so as to prevent blocking together with protection of the weathered material. No-fines concrete whilst appearing to be suitable to protect weathered zones often ends up with lower permeability than designed and should not be relied upon without some additional drainage measures.

\subsection{Reinforcement}

The factor of safety against slab sliding can be improved by a variety of options. For sheeting joints specifically, provided there has not been previous movement, the rough interlocking nature of these tension fractures provides considerable shear strength (where not severely weathered) and this needs to be accounted for in design in order to avoid over-conservatism. If the joint can be prevented from sliding by reinforcing at strategic locations then full advantage can be taken of the considerable natural frictional resistance. Active stabilisation of blocks is possible if they are of relatively small size and access is feasible either by rope access techniques down the slope, using "spyder" drills or even better if tracks can be constructed, using more conventional drilling equipment. Depending on configuration, rock blocks may be stabilised by dowelled concrete buttressing (to provide direct support to a welldefined potential release block), through various forms of tie-down and/or overturning control tie-back reinforcement, comprising deep sub-vertical dowelling. Sub-horizontal cable anchors can be used if capacities larger than about 20 tonnes per reinforcement member are required. Often the most significant reinforcement is needed where extensive sheeting joint zones define slabs of large proportions. In such cases, the preferred method in Hong Kong is to use passive dowel designs rather than tensioned bolting for necessary shear constraint. This is because it is considered that active reinforcement members are more subject to corrosion damage and that passive dowels allow both mobilisation of a normal force (due to the restraint provided by the full column bond against asperity ride during shear), plus active shear restraint provided by the steel of the dowels resisting block slide mobilisation (Spang and Egger 1990).

The Geotechnical Engineering Office in Hong Kong has published some guidelines on prescriptive measures for 
rock slopes and in particular gives guidance on rock dowelling for rock blocks with volume less than $5 \mathrm{~m}^{3}$ (Yu et al. 2005). In essence, it is advised to use pattern dowels with one dowel per $\mathrm{m}^{3}$ of rock to be supported with minimum and maximum lengths of 3 and $6 \mathrm{~m}$, respectively and where the potential sliding plane dips at less than $60^{\circ}$. The dowels are to be installed at right angles to the potential sliding plane, with the key intention to allow the dowels to act in shear, whilst also enhancing the normal restraint due to asperity ride during sliding. In practice dowels frequently need to be used in more variable orientations.

It is often difficult to identify the thickness and volume of a given block requiring support and therefore dowel patterns frequently are based on some assessment of crossjoint spacing. Along the Tuen Mun Highway, typical support layouts were adopted based on field mapping of cross-joint spacing and orientation with respect to the sheeting joint geometry and inferred direction of sliding. The design used 40-mm dowels at 5-m spacing, based on analysis using the approach of Spang and Egger (1990) for definition of shear resistance. In areas of closer cross joints, 25-mm dowels were used at 2-m spacing, split spaced between the wider pattern bolting layouts (Pine and Roberds 2005). Field placement of reinforcement was however always double checked against natural disposition of features and decisions made by the engineer in the field for additional spot bolting or dowelling as required and illustrated in Fig. 29.

\subsection{Buttressing}

Where earlier failure or cutting exposes sheeting joints or detached blocks resting on a sheet structure then buttressing using a reinforced concrete wall or a raked structural prop may be an economic option and offer some certainty of solving potential sliding or toppling instability problems. One example is shown in Fig. 30. Much of the slope illustrated has sheeting joints running through it. The slope

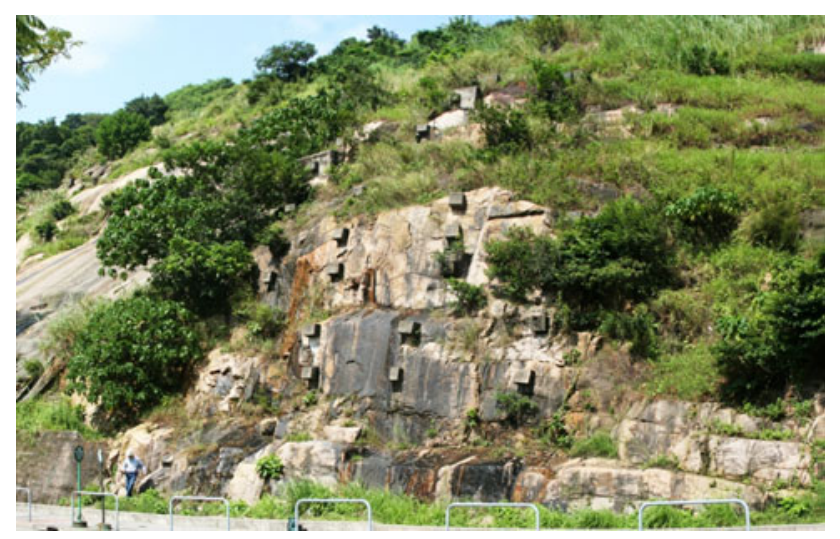

Fig. 29 Spot bolting of sheeting joint slabs
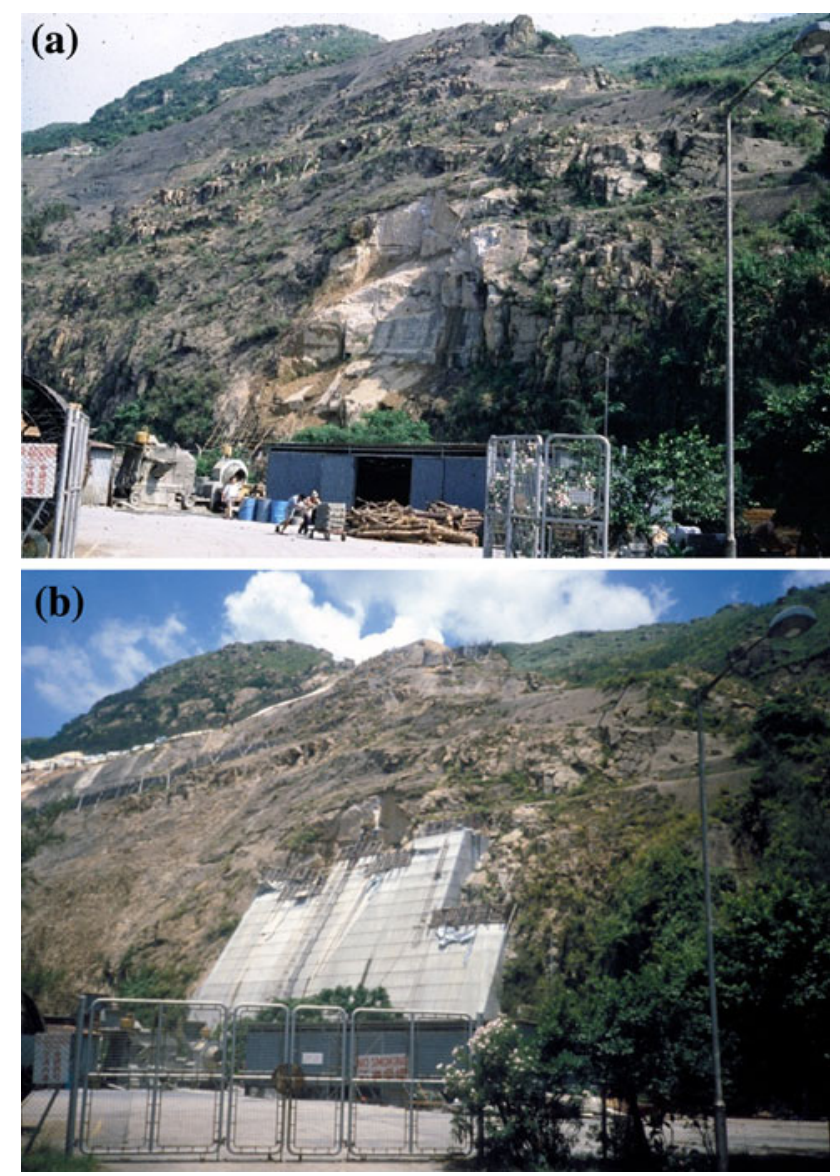

Fig. 30 Tsing Yi Island, Hong Kong. $500 \mathrm{~m}^{3}$ rock fall from sheeting joints: a debris cleared off and showing the extent of problem with extensive sheeting joints through the hillside; b the solution: a huge concrete buttress

failed progressively over a period of 2 years and the eventual solution was to fill the failed zone with a very large concrete buttress wall.

Figure 31 is a sketch of a large cut slope in Kwun Tong, Hong Kong, which was the location for numerous significant failures along sheeting joints over several years. The slope was investigated by subsurface boreholes and by face mapping and sections of the slope were designed to be reprofiled, soil nailed, dowelled and buttressed as appropriate. During construction however an additional sheeting joint was exposed unexpectedly and found to be partly open and partly infilled with stream sediments (Fig. 32). It was established by careful mapping and matching geological features such as mineral veins across the joint that, despite the voids and sediment infill, the joint had not been displaced but simply eroded internally and locally. It was decided that the peak interlocking strength could still be relied upon and the solution adopted was to restrict any translational movement. Accordingly, a dowelled buttress wall was constructed to infill the area below the potential 
Fig. 31 Sketch of large section of rock slope along Kwun Tong Road (slopes up to $30 \mathrm{~m}$ high) with history of failures dominated by sliding on sheeting joints and selected for engineering upgrading work

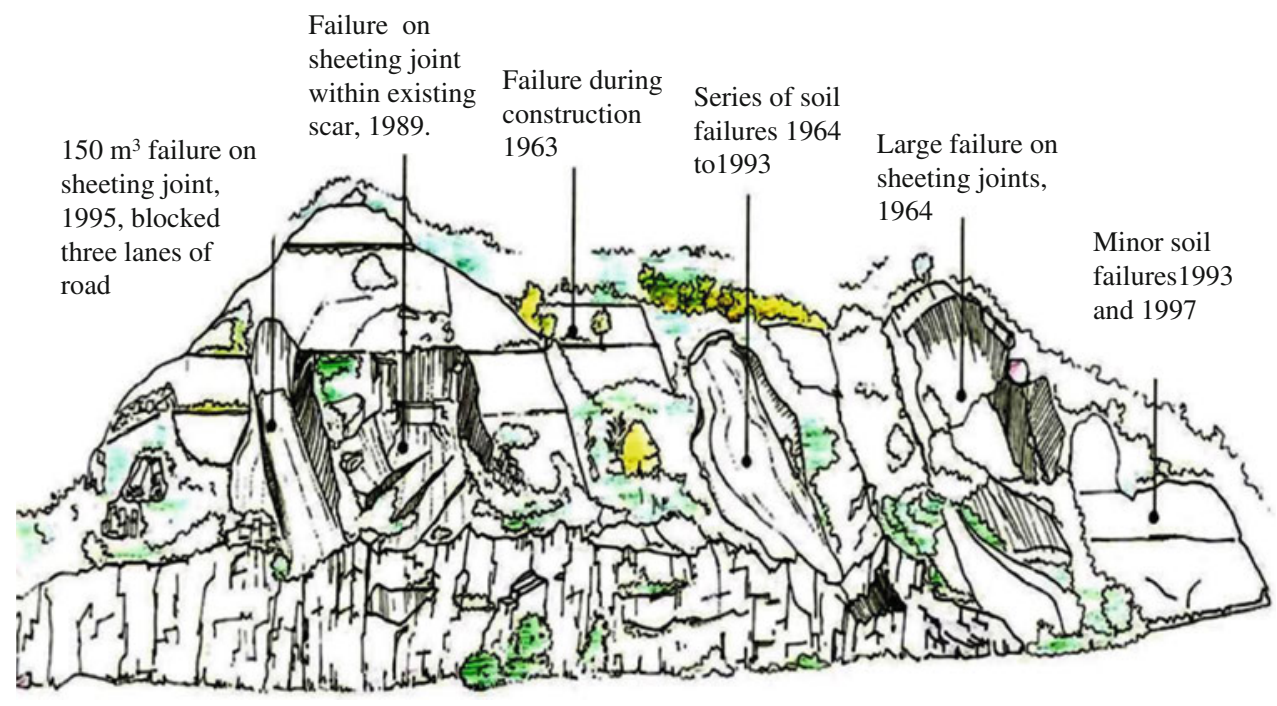

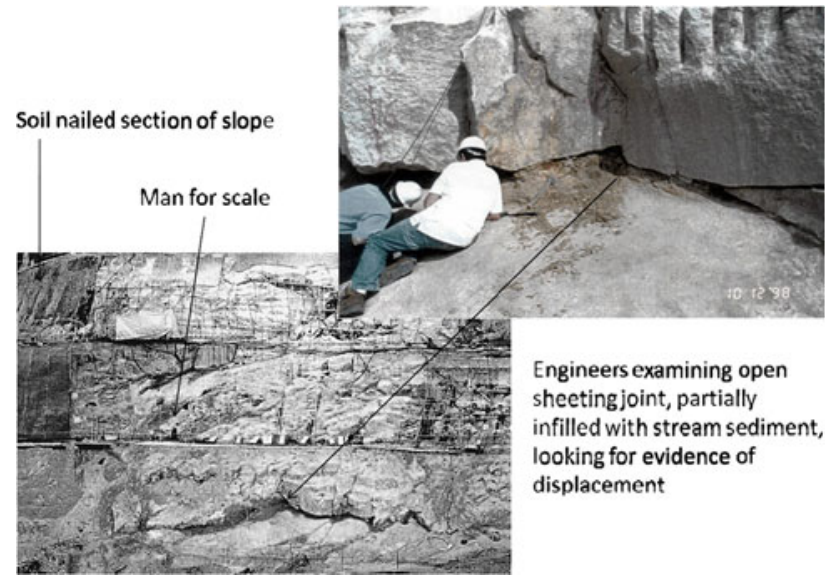

Fig. 32 Landslide preventive works underway at Kwun Tong, Hong Kong

sliding slab with careful attention to ensure that the underground stream could continue to flow without restriction.

Similarly on the slopes above Tuen Mun Highway many combination buttresses were employed with parts of blocks dowelled and part buttressed as access and local geometry dictated.

\section{Conclusions}

Sheeting joints develop due to topographical or residual tectonic stresses close to the Earth's surface. Those that develop in natural slopes are often of adverse geometry with respect to natural hillside slopes and as such, may predispose the slope to repeated failure. Sheeting joint terrain often comprises a series of simple slabs resting on one another and often these are geologically young. Many other sheeting joints are very old however, as evidenced by their association with deep weathering profiles, by the propagation of other fracture systems through the rock mass after formation of the sheeting joints and from geomorphological interpretation.

Sheeting joints appear to always have originated by tensile opening and as such often occur as persistent, mechanical fractures extending laterally over many tens to even hundreds of metres. Detailed assessment of the configuration of sheeting slabs on various slopes in Hong Kong, Korea and other well-defined sheeting geologies around the world, suggests that in general, remnant slabs sitting on persistent sheet structures owe their stability more to the roughness and undulating/wavy character of the sheet structure (and associated dilation) rather than to rock bridges (and true cohesion) which is commonly the case for other types of joints. Definition of controlling shear strength is thus amenable to evaluation either through a testing programme combined with field measurement and assessment of roughness and analysis of the way that roughness will cause dilation or by employing empirical methods. Both approaches require considerable judgement.

Rock slope failure mechanisms based mainly on pseudostatistical analysis of defect data should not be the sole basis of defining ground models. More intelligent analysis of the data is required and in the case of sheeting joints, recognition of lateral variation in orientation, roughness and degree of weathering and openness. The possibility for composite landslides, partly involving rough joints and partly through more weathered sections should be recognised. It is clear that sheeting joint failures are often associated with the development of cleft water pressures and that failure may be incremental over long periods and many storm events.

Landslide preventive works often necessitate reinforcement, drainage and rockfall protection (such as fences, 
catch nets and ditches). On steep hill slopes where detached or partially detached sheeting structures exist, buttresses and/or anchor blocks have application for preventing initial movement that would otherwise lead to progressive deterioration. Preventing initial movement will optimise the contribution from peak shear strength. Seepage points on faces can help to identify the likely routes for channel flow which should be targeted with raking drains.

Acknowledgments This research was supported in part by a grant (NEMA-06-NH-05) from the Natural Hazard Mitigation Research Group, National Emergency Management Agency (NEMA), Ministry of Public Administration and Security, Korea.

Open Access This article is distributed under the terms of the Creative Commons Attribution Noncommercial License which permits any noncommercial use, distribution, and reproduction in any medium, provided the original author(s) and source are credited.

\section{References}

Archambault G, Verreault N, Riss J, Gentier S (1999) Revisiting Fecker-Rengers-Barton's methods to characterize joint shear dilatancy. In: Amadei B, Kranz RL, Scott GA, Smeallie PH (eds) Rock mechanics for industry. Balkema, Rotterdam, pp 423-430

Baecher GB, Christian JT (2003) Reliability and statistics in geotechnical engineering. Wiley and Sons, $605 \mathrm{p}$

Bahat D, Grossenbacher K, Karasaki K (1999) Mechanism of exfoliation joint formation in granitic rocks, Yosemite National Park. J Struct Geol 21:85-96

Bandis SC (1980) Experimental studies of scale effects on the shear strength, and deformation of rock joints. Unpublished $\mathrm{PhD}$ thesis, The University of Leeds, 385 p plus 4 appendices

Bandis SC, Lumsden AC, Barton NR (1981) Experimental studies of scale effects on the shear behaviour of rock joints. Int J Rock Mech Min Sci Geomech Abstr 18:1-21

Barton NR (1973) Review of a new shear-strength criterion for rock joints. Eng Geol 7:287-332

Barton NR (1990) Scale effects or sampling bias? In: Proceedings of 1st international workshop on scale effects in rock masses. Loen, Norway, pp 31-55

Barton NR, Bandis SC (1990) Review of predictive capabilities of JRC-JCS model in engineering practice. In: Barton N, Stephansson $\mathrm{O}$ (eds) Rock joints, proceedings international symposium on rock joints, Loen, Norway. Balkema, Rotterdam, pp 603-610

Beer AJ, Stead D, Coggan JS (2002) Estimation of the joint roughness coefficient (JRC) by visual comparison. Rock Mech Rock Eng 35:65-74

Brady BHG, Brown ET (1985) Rock mechanics for underground mining. George Allen and Unwin, London, $527 \mathrm{p}$

Brand EW, Hencher SR, Youdan JD (1983) Rock slope engineering in Hong Kong. In: Proceedings of the 5th international rock mechanics congress, Melbourne, C, 17-24

Brown RHA (1999) The management of risk in the design and construction of tunnels. Korean Geotechnical Society, Tunnel Committee Seminar, 21st Seminar, 21st September, $22 \mathrm{p}$

Brown ET (2008) Estimating the mechanical properties of rock masses. In: Potvin Y, Carter J, Dyskin A, Jeffrey R (eds) Proceedings, 1st southern hemisphere international rock mechanics symposium, Perth, 16-19 September, vol 1, pp 3-22

BS 5930 (1999) Code of practice for site investigation. $206 \mathrm{p}$
Byerlee J (1978) Friction of rocks. Pure Appl Geophys 116:615-626

Carter TG, Mierzejewski J, Kwong AKL (1998) Site investigation for rock slope excavation and stabilization adjacent to a major highway in Hong Kong. In: Proceedings international conference on urban ground engineering, session 2, Geotechnics, Paper 14, $10 \mathrm{pp}$

Carter TG, de Graaf P, Booth P, Barrett S, Pine R (2002) Integration of detailed field investigations and innovative design key factors to the successful widening of the Tuen Mun Highway. In: Proceedings of the 22nd annual seminar, organised by the Geotechnical Division of the Hong Kong Institution of Engineers, 8th May, 2002, pp 187-201

Carter TG, Diederichs MS, Carvalho JL (2008) Application of modified Hoek-Brown transition relationships for assessing strength and post-yield behaviour at both ends of the rock competence scale. Proc SAIMM 108(6):325-338

Carvalho JL, Carter TG, Diederichs MS (2007) An approach for prediction of strength and post yield behaviour for rock masses of low intact strength. In: Proc 1st Can-US Rock Symp Meeting society's challenges and demands. Vancouver, pp 249-257

Cloos H (1922) Tectonik und magma. Bd I Abh d Preuss Geol Land, 89

Diederichs MS (2003) Rock fracture and collapse under low confinement conditions. Rock Mech Rock Eng 36:339-381

El-Ramly H, Morgenstern NR, Cruden DM (2005) Probabilistic assessment of stability of a cut slope in residual soil. Géotechnique 55(1):77-84

Fecker E, Rengers N (1971) Measurement of large scale roughness of rock planes by means of profilograph and geological compass. In: Proceedings symposium on rock fracture, Nancy, France, Paper 1-18

Geotechnical Engineering Office (1988) Guide to rock and soil descriptions. (Geoguide 3). Geotechnical Engineering Office, Hong Kong, 189 p. Available at http://www.cedd.gov.hk/eng/ publications/manuals/manu_eg3.htm

Geotechnical Engineering Office (2000a) Highway slope manual. Geotechnical Engineering Office, Hong Kong, 114 p. Available at http://www.cedd.gov.hk/eng/publications/manuals/manu_em2. htm

Geotechnical Engineering Office (2000b) Technical guidelines on landscape treatment and bio-engineering of man-made slopes and retaining walls. GEO Publication No. 1/2000, Geotechnical Engineering Office, Hong Kong, 146 p. Available at http:// www.cedd.gov.hk/eng/publications/manuals/manu_ep1.htm

Goodman RE (1980) Introduction to rock mechanics. Wiley and Sons, New York

Hack R (1998) Slope stability probability classification, SSPC, 2nd edn. International Institute for Aerospace Survey and Earth Sciences (ITC), Publication No. 43, $258 \mathrm{p}$

Halcrow Asia Partnership Ltd (1998) Report on the landslide at Ten Thousand Buddha's Monastery of 2 July 1997. GEO Report No. 77, Geotechnical Engineering Office, Hong Kong, 96 p. http:// www.cedd.gov.hk/eng/publications/geo_reports/geo_rpt077.htm

Halcrow China Ltd (2002a) Investigation of some selected landslides in 2000 (Volume 1). GEO Report No. 129, Geotechnical Engineering Office, Hong Kong, 144 p. Available at http:// www.cedd.gov.hk/eng/publications/geo_reports/geo_rpt129.htm

Halcrow China Ltd (2002b) Investigation of some selected landslides in 2000 (Volume 2). GEO Report No. 130, Geotechnical Engineering Office, Hong Kong, 173 p. Available at http:// www.cedd.gov.hk/eng/publications/geo_reports/geo_rpt130.htm

Halcrow China Ltd (2002c) Study on the provision of temporary protective barriers and associated measures and methods of and the supervision to be specified and provided for rock breaking operations. Unpublished Report to the Geotechnical Engineering Office, Hong Kong Government 
Hencher SR (1976) Correspondence: a simple sliding apparatus for the measurement of rock friction. Géotechnique 26(4):641-644

Hencher SR (1983) Landslide studies 1982 case study no. 2 Junk Bay Road. Special project report no SPR 3/83, Geotechnical Control Office, Hong Kong, $32 \mathrm{p}$

Hencher SR (1995) Interpretation of direct shear tests on rock joints. In: Daeman JJK, Schultz RA (eds) Proceedings 35th US symposium on rock mechanics. Lake Tahoe, pp 99-106

Hencher SR (2006) Weathering and erosion processes in rockimplications for geotechnical engineering. In: Proceedings symposium on Hong Kong soils and rocks, March 2004, Institution of Mining, Metallurgy and Materials and Geological Society of London, pp 29-79

Hencher SR (2010) Preferential flow paths through soil and rock and their association with landslides. Hydrol Process (in press)

Hencher SR, Knipe RJ (2007) Development of rock joints with time and consequences for engineering. In: Proceedings of the 11th congress of the international society for rock mechanics, vol 1 , pp 223-226

Hencher SR, Richards LR (1982) The basic frictional resistance of sheeting joints in Hong Kong Granite. Hong Kong Eng 11(2):21-25

Hencher SR, Richards LR (1989) Laboratory direct shear testing of rock discontinuities. Ground Eng 22(2):24-31

Hencher SR, Toy JP, Lumsden AC (1993) Scale dependent shear strength of rock joints. In: da Cunha P (ed) Scale effects in rock masses 93. Balkema, Rotterdam, pp 233-240

Hoek E (1968) Brittle failure of rock. In: Stagg KG, Zienkiewicz OC (eds) Rock mechanics in engineering practice. Wiley and Sons, London, pp 99-124

Hoek E (2009) A slope stability problem in Hong Kong. Published online at http://www.rocscience.com/hoek/pdf/7_A_slope_ stability_problem_in_Hong_Kong.pdf

Holzhausen GR (1989) Origin of sheet structure, 1. Morphology and boundary conditions. Eng Geol 27:225-278

International Society for Rock Mechanics (1978) Suggested methods for the quantitative description of discontinuities in rock masses. Int J Rock Mech Min Sci Geomech Abstr 15(6):319-368

Jahns RH (1943) Sheet structure in granites, its origin and use as a measure of glacial erosion in New England. J Geol 51:71-98

Johnson AM (1970) Formation of sheet structure in granite, chap 10. In: Physical processes on geology, Freeman Cooper and Company

Kikuchi K, Mito Y (1993) Characteristics of seepage flow through the actual rock joints. In: Proceedings 2nd international workshop on scale effects in rock masses, Lisbon, pp 305-312

Kulatilake PHSW, Shou G, Huang TH, Morgan RM (1995) New peak shear strength criteria for anisotropic rock joints. Int J Rock Mech Min Sci Geomech Abstr 32:673-697

Kveldsvik V, Nilsen B, Einstein HH, Nadim F (2008) Alternative approaches for analyses of a $100,000 \mathrm{~m}^{3}$ rock slide based on Barton-Bandis shear strength criterion. Landslides 5:161-176

Martel SJ (2006) Effect of topographic curvature on near-surface stresses and application to sheeting joints. Geophys Res Lett 33:LO1308

Nichols T C Jr (1980) Rebound, its nature and effect on engineering works. Q J Eng Geol 13:133-152

Nicholson GA (1994) A test is worth a thousand guesses-a paradox. In: Nelson PP, Laubach SE (eds) Proc 1st NARMS symposium, pp 523-529

Ollier CD (1975) Weathering. Longman, 304 p

Papaliangas TT, Hencher SR, Lumsden AC (1994) Scale independent shear strength of rock joints. In: Proceedings IV CSMR/integral approach to applied rock mechanics, Santiago, Chile, pp 123133
Papaliangas TT, Hencher SR, Lumsden AC (1995) A comprehensive peak strength criterion for rock joints. In: Proceedings 8th international congress on rock mechanics, Tokyo, vol 1, pp 359366

Parry S, Campbell SDG, Fletcher CJN (2000) Kaolin in Hong Kong saprolites-genesis and distribution. In: Proceedings conference engineering geology HK 2000, IMM HK Branch, pp 63-70

Patton FD (1966) Multiple modes of shear failure through rock. In: Proceedings 1st international congress international society rock mechanics, Lisbon, vol 1, pp 509-513

Patton FD, Deere DU (1970) Significant geological factors in rock slope stability. In: Proceedings symposium on planning open pit mines, Johannesburg, A.A. Balkema, pp 143-151

Pine RJ, Roberds WJ (2005) A risk-based approach for the design of rock slopes subject to multiple failure modes-illustrated by a case study in Hong Kong. Int J Rock Mech Min Sci 42:261-275

Rabinowicz E (1965) Friction and wear of materials. John Wiley, New York

Richards LR, Cowland JW (1982) The effect of surface roughness on the field shear strength of sheeting joints in Hong Kong granite. Hong Kong Eng 10(10):39-43

Richards LR, Cowland JW (1986) Stability evaluation of some urban rock slopes in a transient groundwater regime. In: Proceedings conference on rock engineering and excavation in an urban environment, IMM, Hong Kong, pp 357-363 (discussion 501506)

Roorda J, Thompson JC, White OL (1982) The analysis and prediction of lateral instability in highly stressed, near-surface rock strata. Can Geotech J 19(4):451-462

Schneider HJ (1976) The friction and deformation behaviour of rock joints. Rock Mech 8:169-184

Scholtz CH (1990) The mechanics of earthquakes and faulting. Cambridge University Press, Cambridge, $439 \mathrm{p}$

Selby MJ (1993) Hillslope materials and processes, 2nd edn, Oxford University Press, $451 \mathrm{p}$

Simons N, Menzies B, Mathews M (2001) A short course in soil and rock slope engineering. Thomas Telford, $432 \mathrm{p}$

Spang K, Egger P (1990) Action of fully-grouted bolts in jointed rock and factors of influence. Rock Mech Rock Eng 23:201-229

Stimpson B (1981) A suggested technique for determining the basic friction angle of rock surfaces using core. Int J Rock Mech Min Sci Geomech Abstr 18:63-65

Twidale CR (1973) On the origin of sheet jointing. Rock Mech 5:163-187

Twidale CR, Vidal Romani JR (2005) Landforms and geology of granite terrains. Taylor and Francis, $352 \mathrm{p}$

Vidal Romani JR, Twidale CR (1999) Sheet fractures, other stress forms and some engineering implications. Geomorphology 31:13-27

Wakasa S, Matsuzaki H, Tanaka Y, Matskura Y (2006) Estimation of episodic exfoliation rates of rock sheets on a granite dome in Korea from cosmogenic nuclide analysis. Earth Surf Proc Land 31:1246-1256

Wise DU (1964) Microjointing in basement, Middle Rocky Mountains of Montana and Wyoming. Geol Soc Am Bull 75:287-306

Wyllie DC, Mah CW (2004) Rock Slope Engineering, 4th edn, Spon, $431 \mathrm{p}$

Yu YS, Coates DF (1970) Analysis of rock slopes using the finite element method. Department of Energy, Mines and Resources Mines Branch, Mining Research Centre, Research Report, R229 (Ottawa)

Yu YF, Siu CK, Pun WK (2005) Guidelines on the use of prescriptive measures for rock slopes. GEO Report 161, $34 \mathrm{p}$ 